\title{
IDENTIFYING THE ROLE OF LABOR MARKETS FOR MONETARY POLICY IN AN ESTIMATED DSGE MODEL
}

by Kai Christoffel, Keith Kuester and Tobias Linzert 
EUROPEAN CENTRAL BANK

\title{
WORKING PAPER SERIES
}

NO 635 I JUNE 2006

\author{
IDENTIFYING THE \\ ROLE OF LABOR \\ MARKETS FOR \\ MONETARY POLICY \\ IN AN ESTIMATED \\ DSGE MODEL'
}

\author{
by Kai Christoffel ${ }^{2}$, \\ Keith Kuester ${ }^{3}$ \\ and Tobias Linzert ${ }^{4}$
}

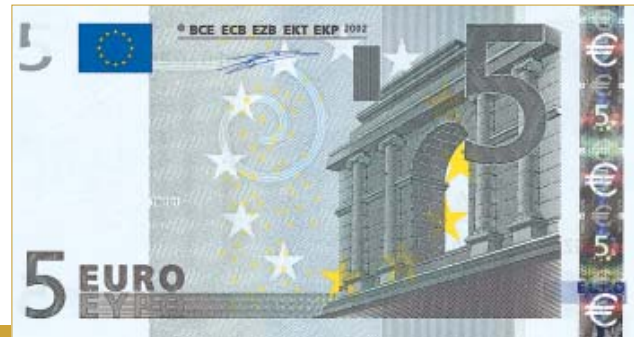

In 2006 all ECB

publications

will feature

will feature

from the

$€ 5$ banknote. http://www.ecb.int or from the Social Science Research Network electronic library at http://ssrn.com/abstract_id $=905080$

I A previous version of this paper, circulated as IZA Discussion Paper No. 1902, was titled "The Impact of Labor Markets on the Transmission of Monetary Policy in an Estimated DSGE Model". We thank participants of the Bundesbank workshop on "Dynamic Macroeconomic Modelling" in Frankfurt, September 20th, 2005. Especially, we are indebted to Michael Krause and to Olivier Pierrard for their thorough discussions of the paper. We would also like to thank seminar participants at the European Central Bank and the Network for Quantitative Macroeconomics. We are furthermore grateful for comments by and discussions with Heinz Herrmann, Philip Jung, Thomas Lubik and Ernest Pytlarczyk. Kuester would like to thank the Bundesbank for its hospitality and financial support during part of this research project. Our code used Dynare 3.0 as a starting point. The views expressed in this paper are those of the authors. The opinions expressed do not necessarily reflect the views of the Bundesbank or the European Central Bank. 2 DG Research, European Central Bank, Kaiserstrasse 29, 603 II Frankfurt am Main, Germany; phone: +49-69-1344-8939; e-mail: kai.christoffel@ecb.int 3 Goethe University, Mertonstrasse I7, PB 94, 60054 Frankfurt am Main, Germany; phone: +49-69-798-25283; e-mail: kuester@wiwi.uni-frankfurt.de 
(C) European Central Bank, 2006

\section{Address}

Kaiserstrasse 29

60311 Frankfurt am Main, Germany

\section{Postal address}

Postfach 160319

60066 Frankfurt am Main, Germany

\section{Telephone}

+496913440

\section{Internet}

http://www.ecb.int

\section{Fax}

+496913446000

\section{Telex}

$411144 \mathrm{ecb} d$

All rights reserved.

Any reproduction, publication and reprint in the form of a different publication, whether printed or produced electronically, in whole or in part, is permitted only with the explicit written authorisation of the ECB or the author(s).

The views expressed in this paper do not necessarily reflect those of the European Central Bank.

The statement of purpose for the ECB Working Paper Series is available from the ECB website, http://www.ecb.int.

ISSN 1561-0810 (print)

ISSN 1725-2806 (online) 


\section{CONTENTS}

Abstract

Non-technical summary

1 Introduction

2 The model

2.1 Households' consumption and saving decision

2.2 Production

2.2.1 Intermediate goods producers

2.2.2 Wholesale sector

2.2.3 Retail firms

2.3 The wage-inflation channel in the linearized model

2.4 Monetary policy

3 Calibration and priors

4 Estimation results

5 The labor market and the dynamics of the economy

6 Conclusions

References

A Linearized model

B Data

C Further estimation statistics for the parameters

D Cross-correlation

E Flexible labor market experiments

F Nominal wage adjustment costs and Calvo wage rigidity 


\begin{abstract}
We focus on a quantitative assessment of rigid labor markets in an environment of stable monetary policy. We ask how wages and labor market shocks feed into the inflation process and derive monetary policy implications. Towards that aim, we structurally model matching frictions and rigid wages in line with an optimizing rationale in a New Keynesian closed economy DSGE model. We estimate the model using Bayesian techniques for German data from the late 1970s to present. Given the pre-euro heterogeneity in wage bargaining we take this as the first-best approximation at hand for modelling monetary policy in the presence of labor market frictions in the current European regime. In our framework, we find that labor market structure is of prime importance for the evolution of the business cycle, and for monetary policy in particular. Yet shocks originating in the labor market itself may contain only limited information for the conduct of stabilization policy.
\end{abstract}

JEL Classification System: E32, E52, J64, C11.

Keywords: Labor market, wage rigidity, bargaining, Bayesian estimation. 


\section{Non-technical Summary}

Employment is the most important factor of economic activity. The efficient functioning of the labor market, i.e. matching workers and employment opportunities, crucially determines the smooth adjustment of economic activity to exogenous shocks. Hence, the labor market may be key for understanding business cycle fluctuations and for understanding the implications for monetary policy in particular. In this light labor markets recently have received considerable interest in the business cycle literature, see e.g. Hall (2005) and Shimer (2005), Trigari (2004) and Blanchard and Gali (2005). Especially European labor markets tend to be characterized by high and prolonged unemployment and inflexible wages. Against this background we quantitatively assess the role which rigid labor markets play for conducting monetary policy in a stable European inflation environment.

Our model reproduces key features of the data by including two prominent rigidities in the labor market. First, firms may not be able to instantaneously find new employees and, similarly, workers have to search for jobs. Second, real wage rigidities hinder wage adjustments and shift the labor market adjustment from prices to quantities. In the framework we propose, wages translate into firms' marginal costs which establishes a direct channel from wages to inflation dynamics via the New Keynesian Phillips curve.

While some studies partially analyze the impact of labor market frictions and wage rigidities on business cycle dynamics in New Keynesian models (see, e.g., Christoffel and Linzert, 2005, and Braun, 2005) we proceed a step further by embedding above rigidities into a dynamic stochastic general equilibrium (DSGE) model which we then estimate as a whole using Bayesian full information techniques as in Smets and Wouters (2003). To circumvent the pre-euro heterogeneity with respect to labor market institutions and monetary policy we base the estimation on German time series. With this well-calibrated framework at hand we assess the role of the labor market for the dynamics of the European economy and derive implications for monetary policy.

We first use the estimated model to explore the question of how the labor market regime affects the transmission process of monetary policy. Adjustments in the labor market, e.g. the flows in and out of employment or the dynamics of real wages will affect the overall transmission of monetary 
policy to inflation. The marginal cost of labor input is influenced, for example, by the degree of nominal wage rigidity, the speed with which idle labor resources can be put to work and by the cost of searching for workers. Firms' marginal cost in turn determine their price setting behavior and thus drive aggregate inflation dynamics. In this exercise we therefore consider different degrees of (real) wage rigidity and different levels of labor market flexibility.

Second we turn to examine how labor market shocks themselves influence business cycle dynamics. In particular, we analyze how shocks in the labor market affect the evolution of employment and output on the one hand and inflation dynamics on the other hand. If indeed shocks originating in the labor market were to strongly affect production and prices, these shocks would constitute valuable information for monetary stabilization policy. Third and finally, our study includes a careful sensitivity analysis with respect to the way the wage rigidity is modelled.

Our results can be summarized as follows. First, we find that the structure of the labor market matters substantially for the overall behavior of the economy and the transmission of monetary policy on inflation in particular. The specific settings of the labor market, as for example the degree of wage inertia or the efficiency of the worker-firm matching process, are found to have a notable impact. Specifically, we find that the degree of wage rigidity leads to more inflation persistence. Moreover, if due to institutional reasons jobs are harder to find, shocks to inflation will die out more slowly. Furthermore we find that a higher degree of wage rigidity amplifies real adjustment in the labor market implying stronger fluctuations in employment.

Second, the realization of labor market shocks has an impact on the labor market itself but a limited influence on the other blocks of the model economy. Therefore labor market shocks do not contribute much to the cyclical dynamics of non-labor market variables - particularly inflation. This suggests that the model does not feature much transmission from labor markets to the rest of the economy. In our model, consumers perfectly insure each other against shortfalls of consumption due to unemployment. Easing this assumption would likely introduce further transmission. In addition, a further natural candidate for a change in the model structure is more closely tying price setting decisions to decisions in the labor market like hiring and wage setting. In total, to the extent the European Central Bank's task is to keep inflation low (and stable), 
policy makers need to have a good understanding of the structure of the labor-market. The realization of labor market specific shocks, however, to a first (coarse) approximation does not appear to contain much information for the conduct of monetary policy if its aim is to achieve stable inflation and to stabilize output around its long-run trend.

Pointing to future research, this latter conclusion comes with the proviso that we leave aside one important welfare-theoretic consideration: while labor market shocks may not alter actual output, they can have a bearing on natural (flex-price) or efficient output, see e.g. Blanchard and Gali (2005). This would in turn matter for the conduct of truly optimal monetary policy. We are currently exploring this point in ongoing research. 


\section{Introduction}

Employment is the most important factor of economic activity. The labor market is therefore crucial for understanding business cycle fluctuations and for understanding the implications for monetary policy in particular. In this light labor markets recently have received considerable interest in the business cycle literature, see e.g. Hall (2005) and Shimer (2005), Trigari (2004) and Blanchard and Gali (2005). Especially European labor markets tend to be characterized by high and prolonged unemployment and inflexible wages. Against this background we quantitatively assess the role which rigid labor markets play for conducting monetary policy in a stable European inflation environment.

Our model reproduces key features of the data by including two prominent rigidities in the labor market. First, matching frictions produce equilibrium unemployment as in Mortensen and Pissarides (1994). Second, real wage rigidities in the form of staggered right-to-manage wage bargaining shift the labor market adjustment from prices to quantities. ${ }^{1}$ While some studies partially analyze the impact of labor rigidities on business cycle dynamics in New Keynesian models (see, e.g., Christoffel and Linzert, 2005, and Braun, 2005) we proceed a step further by embedding above rigidities into a DSGE model which we then estimate using Bayesian full information techniques as in Smets and Wouters (2003). With this well-calibrated framework at hand we assess the role of the labor market for the dynamics of the European economy and derive implications for monetary policy.

In this paper, we specifically aim to disentangle policy implications of the role of labor market structure from the role of labor market shocks. We explore how monetary policy affects aggregate inflation dynamics in labor market regimes characterized by different degrees of wage and employment flexibility. Using the results of the full information Bayesian estimation of the model we also investigate how labor market shocks affect business cycle dynamics and draw conclusions for monetary policy.

\footnotetext{
${ }^{1}$ The introduction of a wage rigidity into the matching framework follows the intuition of Hall (2005) and Shimer (2004). Our approach contrasts with Gertler and Trigari (2005) in that we are able to retain the intensive margin of employment.
} 
Our focus is explicitly on a quantitative analysis of rigid labor markets in an environment of a stable monetary policy regime. To circumvent the pre-euro heterogeneity with respect to labor market institutions and monetary policy we base the estimation on German time series. The German economy serves as a particular well suited example for an economy with a rigid labor market in an environment of a stable monetary policy regime.

We first use the estimated model to explore the question of how the labor market regime affects the transmission process of monetary policy. Adjustments in the labor market, e.g. the flows in and out of employment or the dynamics of real wages will affect the overall transmission of monetary policy to inflation. The marginal cost of labor input is influenced, for example, by the degree of nominal wage rigidity, the speed with which idle labor resources can be put to work and by the cost of searching for workers. Firms' marginal cost in turn determine their price setting behavior and thus drive aggregate inflation dynamics via the New Keynesian Phillips curve. In this exercise we therefore consider different degrees of (real) wage rigidity and different levels of labor market flexibility.

Second we turn to examine how labor market shocks themselves influence business cycle dynamics. In particular, we analyze how shocks in the labor market affect the evolution of employment and output on the one hand and inflation dynamics on the other hand. If indeed shocks originating in the labor market were to strongly affect production and prices, these shocks would constitute valuable information for monetary stabilization policy. Third and finally, our study includes a careful sensitivity analysis with respect to the way the wage rigidity is modeled.

Our main results are summarized as follows. First and in line with the literature (e.g. Christoffel and Linzert, 2005, and Trigari, 2004), the underlying structure of the labor market significantly affects the transmission of monetary policy. In our framework, the right-to-manage wage bargaining establishes a direct channel from wages to inflation. We can therefore show that the degree of real wage rigidity is crucial for the dynamics of inflation after a monetary policy shock. This is due to the fact that under The impact of the labor market structure on aggregate consumption is, however, rather limited. Second, in our model labor market shocks are not decisive for the dynamics of output and inflation at business cycle frequencies. Therefore, to a first (and admit- 
tedly coarse) approximation monetary policy need not react to labor market specific shocks via its interest rate rule. ${ }^{2}$ Third, our results do not seem to be sensitive to the particular way in which we model the wage rigidity.

The remainder of the paper is organized as follows: Section 2 lays out the theoretical model. Section 3 shows the Bayesian calibration and priors for the following estimation. Estimation results are given in Section 4. Section 5 discusses the results in terms of the interrelation of labor markets and monetary policy transmission. Section 6 offers conclusions and an outlook for further research.

\section{The Model}

Our analysis builds on a New Keynesian framework augmented by Mortensen and Pissarides (1994) type matching frictions in the labor market and with exogenous separation as in Trigari (2006). ${ }^{3}$ We advance on her model extending it by a number of structural shocks in order to describe the aggregate behaviour of the economy and by allowing for real wage rigidity. As is common in the literature, we focus on a cashless limit economy; cp. Smets and Wouters (2003) and large parts of Woodford (2003).

\subsection{Households' Consumption and Saving Decision}

One-worker households are uniformly distributed on the unit interval and indexed by $i \in(0,1)$. They are infinitely lived and seek to maximize expected lifetime utility by deciding on the level (and intertemporal distribution) of consumption of a bundle of consumption goods, $C_{t}(i)$, and by

\footnotetext{
${ }^{2}$ In general, as stressed by Blanchard and Gali (2005), welfare-based conclusions regarding the optimal design of monetary policy may depend very much on the interaction between real imperfections and shocks in the model. In particular, while actual output may not be affected by labor market shocks potential output - and thus the welfare-relevant gap - could still change.

${ }^{3}$ Separation rates in Germany are constant over the business cycle (see Bachmann, 2005, and the references therein) - we therefore assume that each period a constant fraction of firm-worker relationships splits up for reasons exogenous to the state of the economy. A similar argument for the U.S. is made by Hall (2005).
} 
holding pure discount bonds $B_{t}(i)$,

$$
\max _{\left\{C_{t}(i), B_{t}(i)\right\}} E_{t}\left\{\sum_{j=0}^{\infty} \beta^{j}\left\{\epsilon_{t+j}^{\text {pref }} U\left(C_{t+j}(i), C_{t+j-1}\right)-g\left(h_{t+j}(i)\right)\right\}\right\}, \beta \in(0,1)
$$

subject to the budget constraint

$$
C_{t}(i)+\frac{B_{t}(i)}{P_{t} R_{t}}=D_{t}+B_{t-1}(i) / P_{t}
$$

Here $C_{t}(i)$ marks consumption of the retail consumption bundle by agent $i$. $R_{t}$, which is assumed to be the monetary authority's policy instrument, denotes the gross nominal return on the bond. Households own the firms in the economy, hence are entitled to their profits. Following much of the literature, we assume that households pool their income. There is perfect consumption risk sharing. $D_{t}$ denotes the income each household receives from (a) labor market activity, (b) profits of firms and (c) government transfers, such as unemployment benefits minus lump-sum taxation and payments under the income insurance scheme. Above, $\epsilon_{t}^{p r e f}$ is an i.i.d. shock to the intertemporal elasticity of substitution of consumption. We refer to this shock as the demand shock.

Let $C_{t-1}$ be the aggregate consumption level in period $t-1$. We assume that individual consumption is subject to external habit persistence, indexed by parameter $h_{c} \in[0,1)$,

$$
U\left(C_{t}(i), C_{t-1}\right)=\frac{\left(C_{t}(i)-h_{c} C_{t-1}\right)^{1-\sigma}}{1-\sigma}
$$

As in Abel (1990) households therefore are concerned with "catching up with the Joneses". 4

The first-order conditions can be summarized in the consumption Euler equation

$$
\lambda_{t}=\beta E_{t}\left\{\lambda_{t+1} \frac{R_{t}}{\Pi_{t+1}}\right\}
$$

\footnotetext{
${ }^{4}$ The specification of the utility function is standard, see e.g. Smets and Wouters (2003). A minor modification of the utility function that yields the same first-order approximation to the Euler equation apart from the definition of the shock process is $U\left(C_{t}(i), C_{t-1}\right)=\frac{1}{1-\sigma} C_{t}(i)^{1-\sigma} C_{t-1}^{\sigma h}$. In this case $\lambda_{t}=\epsilon_{t}^{p r e f} C_{t}^{-\sigma} C_{t-1}^{\sigma h}$. A similar specification can be found in Fuhrer (2000). Boldrin, Christiano, and Fisher (2001) argue that the ability of general equilibrium models to fit the equity premium and other asset market statistics is greatly improved by the presence of external habit formation in preferences.
} 
where $\lambda_{t}=\epsilon_{t}^{\text {pref }}\left(C_{t}-h_{c} C_{t-1}\right)^{-\sigma}$ marks marginal utility of consumption and $\Pi_{t}$ is the gross inflation rate. ${ }^{5}$

To complete the description of preferences, disutility of work is characterized by

$$
g\left(h_{t}(i)\right)=\kappa_{h, t} \frac{h_{t}(i)^{1+\phi}}{1+\phi}, \phi>0, \kappa_{h, t}>0
$$

Here, $\kappa_{h, t}$ denotes a serially correlated shock to the disutility of work:

$$
\log \left(\kappa_{h, t}\right)=\log \left(\overline{\kappa_{h}}\right)\left(1-\rho_{\kappa_{h}}\right)+\rho_{\kappa_{h}} \log \left(\kappa_{h, t-1}\right)+\mu_{t}^{\kappa_{h}}, 0<\rho_{\kappa_{h}}<1
$$

where $\mu_{t}^{\kappa_{h}}$ is an i.i.d. innovation.

\subsection{Production}

New Keynesian models assume that prices are costly to adjust and that firms behave optimally conditional on the given cost structure. This leads to different firms in the economy having different prices and hence facing different demand. Following the literature (see e.g. Trigari, 2006), in order to avoid complications we part the markup pricing decision from the labor demand decision. For an application which operates with firm-specific labor and a matching market in the price setting sector, see Kuester (2006).

There are three types of firms. Intermediate good producing firms need to find a worker in order to produce. In this sector labor market matching and bargaining occurs. Once a firm and a worker have met, wages are negotiated and firms take hours worked as their sole input to production. Intermediate goods are homogenous. The goods are sold to a wholesale sector in a perfectly competitive market at real price $x_{t}$. Firms in the wholesale sector take only intermediate goods as input, and differentiate those. Subject to price setting impediments à la Calvo (1983), they sell to a final retail sector under monopolistic competition. Retailers bundle differentiated goods to a consumption basket $C_{t}$ and under perfect competition sell this final good to consumers at price $P_{t}$. We next turn to a detailed description of the respective sectors.

${ }^{5}$ Due to consumption insurance and separability of utility in consumption and hours worked, all households in equilibrium will have the same consumption levels. We therefore suppress index $i$ wherever the index is not necessary for the context. 


\subsubsection{Intermediate Goods Producers}

There is an infinite number of potential intermediate goods producers. Intermediate goods are homogenous. Firms in production are symmetric one-worker firms. Before entering production, firms currently out of production have to decide whether they want to incur a real search cost/vacancy posting cost to stand a chance of recruiting a worker. This cost is labeled $\kappa_{t} / \lambda_{t}>0 .{ }^{6}$ We assume that vacancy posting costs follow an autoregressive process

$$
\log \left(\kappa_{t}\right)=\log (\bar{\kappa})\left(1-\rho_{\kappa}\right)+\rho_{\kappa} \log \left(\kappa_{t-1}\right)+\mu_{t}^{\kappa}, 0<\rho_{\kappa}<1
$$

where $\mu_{t}^{\kappa}$ is an i.i.d. innovation. Let $V_{t}$ be the market value of a prototypical firm out-of-production in $t$ and $J_{t}$ the value of a firm in $t$ that already found a worker prior to period $t,^{7}$ then

$$
V_{t}=-\frac{\kappa_{t}}{\lambda_{t}}+E_{t}\left\{\beta_{t, t+1} q_{t}(1-\rho) J_{t+1}\right\}
$$

Here $q_{t}$ denotes the probability of finding a worker in $t$ and $\rho$ is the constant probability that a match is severed for an exogenous reason prior to production in $t+1 . \beta_{t, t+1}:=\beta \frac{\lambda_{t+1}}{\lambda_{t}}$ denotes the equilibrium pricing kernel. ${ }^{8}$

Labor (hours worked) is the only factor of production. Each firm $j$ in the intermediate good sector has the same production technology with decreasing returns to labor

$$
y_{t}^{I}(j)=z_{t} h_{t}(j)^{\alpha}, \alpha \in(0,1) .
$$

Here $y_{t}^{I}(j)$ marks the amount of the homogenous intermediate good produced by firm $j$ and $z_{t}$

\footnotetext{
${ }^{6}$ Since marginal utility of consumption, $\lambda_{t}$ tends to be low in booms and high in recessions, this specification implies procyclical real vacancy posting costs.

${ }^{7}$ Wherever it is clear from the context that variables refer to a specific firm/worker match, as it should be here, we do not index variables by $j$.

${ }^{8}$ In principle, in period $t$ firms that found a worker prior to period $t$ decide whether to produce or not to produce. Our assumption that separation is exogenous means that we abstract from such considerations. However, we retain the point of no production as our threat point in the wage bargaining process. Implicitly therefore we assume that in equilibrium the bargaining set will always be non-empty.
} 
marks the economy wide level of productivity. Intermediate goods producers sell their product in a competitive market at real (in terms of the final good) price $x_{t}$. Labor is paid the real hourly wage rate $w_{t}$. So the value as of period $t$ of a firm, the worker-match of which is not severed prior to production, is given by

$$
J_{t}=\psi_{t}+E_{t}\left\{\beta_{t, t+1}\left[(1-\rho) J_{t+1}+\rho V_{t+1}\right]\right\},
$$

where $\psi_{t}$ is the firm's real per period profit which will be discussed in detail in equation (18).

Vacancy Posting. We assume that there is free entry into production apart from the sunk vacancy posting cost. This insures that ex ante (pre-production) profits are driven to zero in equilibrium, $V_{t}=0$. Together with (6) and (8) this implies the vacancy posting condition

$$
\frac{\kappa_{t}}{\lambda_{t}}=q_{t} E_{t}\left\{\beta_{t, t+1}(1-\rho)\left[\psi_{t+1}+\frac{\kappa_{t+1}}{\lambda_{t+1} q_{t+1}}\right]\right\}
$$

Iterating equation (9) forward shows that real vacancy posting costs in equilibrium equal the discounted expected profit of the firm over the life-time of a match.

Matching. We assume a standard Mortensen and Pissarides (1994) type matching market. Let $u_{t}$ be the fraction of workers (households) searching for employment during period $t$, let $v_{t}$ be the number of vacancies posted in period $t$ as a fraction of the labor force. Firms and workers meet randomly. In each period the number of new matches is assumed to be given by the following constant returns to scale matching function

$$
m_{t}=\sigma_{m} u_{t}^{\sigma_{2}} v_{t}^{1-\sigma_{2}}, \sigma_{2} \in(0,1)
$$

where $\sigma_{m}>0$ can be understood as the efficiency of matching, which is the rate at which firms and workers meet. $\sigma_{2}$ governs the relative weight the pool of searching workers and firms, respectively, receive in the matching process. We define labor market tightness (from the view point of a firm) 
as

$$
\theta_{t}:=\frac{v_{t}}{u_{t}}
$$

The probability that a vacant job will be filled,

$$
q_{t}:=\frac{m_{t}}{v_{t}}=\sigma_{m} \theta_{t}^{-\sigma_{2}}
$$

is falling in market tightness, showing the congestion externality of new vacancies. The probability that a searching worker finds a job,

$$
s_{t}:=\frac{m_{t}}{u_{t}}=\sigma_{m} \theta_{t}^{1-\sigma_{2}}
$$

in turn is increasing in market tightness. Each new searcher decreases market tightness and therefore means a negative labor market tightness externality to other workers searching for employment.

Wage Bargaining Preliminaries. Firms and workers bargain only over wages, taking the firm's labor-demand function as given ("Right-to-manage"). Christoffel and Linzert (2005) demonstrate that in a right-to-manage wage bargaining framework wage persistence may contribute to explain a large part of the observed inflation persistence. This channel is missing under the predominantly used assumption of an efficient bargaining model. We turn to describe each party's surplus from staying matched, which is an integral component of each side's bargaining position. A firm which stays in production receives a period profit $\psi_{t}$ in $t$. With probability $1-\rho$ the current match will not be severed at the beginning of the next period. Due to free entry into vacancy posting, the value of not being matched is always zero. A firm's surplus therefore is

$$
J_{t}-V_{t}=\psi_{t}+E_{t}\left\{\beta_{t, t+1}(1-\rho) J_{t+1}\right\}
$$

An unemployed worker receives real benefits $b$. With probability $s_{t}$ he will find a new firm. Conditional on having found a firm, with probability $(1-\rho)$ this match will survive until production 
Conditional on having found a firm, with probability $(1-\rho)$ this match will survive until production starts. The value of a worker who is not employed but searching during $t$ therefore is

$$
U_{t}=b+E_{t}\left\{\beta_{t, t+1}\left[s_{t}(1-\rho) W_{t+1}+\left(1-s_{t}+s_{t} \rho\right) U_{t+1}\right]\right\}
$$

Taking into account the consumption equivalent value of the disutility of work, $\frac{g\left(h_{t}\right)}{\lambda_{t}}$, the value to the worker when employed during period $t$ and not searching is

$$
W_{t}=w_{t} h_{t}-\frac{g\left(h_{t}\right)}{\lambda_{t}}+E_{t}\left\{\beta_{t, t+1}\left[(1-\rho) W_{t+1}+\rho U_{t+1}\right]\right\}
$$

reflecting the probability of being separated in $t+1$ with probability $\rho$. Hence the marginal increase of family utility through an additional family member in employment, the surplus of being in employment in $t$, is given by ${ }^{9}$

$$
W_{t}-U_{t}=w_{t} h_{t}-\frac{g\left(h_{t}\right)}{\lambda_{t}}-b+E_{t}\left\{\beta_{t, t+1}(1-\rho)\left(1-s_{t}\right)\left(W_{t+1}-U_{t+1}\right)\right\} .
$$

Real Wage Rigidities. Once matched, each period firms and workers negotiate over the real wage rate subject to adjustment costs which need to be born by the firm. A firm's per period profit is defined as

$$
\psi_{t}(j):=x_{t} y_{t}^{I}(j)-w_{t}(j) h_{t}(j)-\frac{1}{2} \phi_{L}\left(w_{t}(j)-w_{t-1}(j)\right)^{2},
$$

where $x_{t}$ is the real price of the intermediate good, $y_{t}^{I}(j)$ is the firm's production level, $w_{t}(j)$ is the prevailing wage rate at firm $j$ and $w_{t-1}(j)$ is last period's firm-specific wage level (or the average wage level if there is no wage history). ${ }^{10}$ Apart from the direct effect on profits, this specification implicitly assumes that firms perceive real wage changes to bring about additional,

\footnotetext{
${ }^{9}$ This can be derived from first principles by assuming that workers value their labor-market actions in terms of the contribution these actions give to the utility of the family to which they belong and with which they pool their income; see Trigari (2006).

${ }^{10}$ We also experimented with nominal (instead of real) wage adjustment costs and with a Calvo-type staggered wage setting mechanism. Qualitatively, our results are not affected by this choice. See Appendices F and F for details.
} 
unambigously negative effects on profits. For example, real wage decreases may be detrimental to worker motivation today. By the same token, real wage increases today on the other hand can be hard to reverse in the future. Parameter $\phi_{L}>0$ indexes how strong this motive is. ${ }^{11}$

With right-to-manage, labor demand is given by the competitive optimality condition that the marginal value product of labor, $x_{t} m p l_{t}$, needs to equal the hourly real wage rate:

$$
x_{t} m p l_{t}=w_{t}, \text { where } m p l_{t}:=z_{t} \alpha h_{t}^{\alpha-1} .
$$

Wage Bargaining, Final Ingredients. Firms and workers seek to maximise the overall rents arising from an existing employment relationship. These rents are distributed according to the bargaining power of workers, $\eta$. Firms and workers, once matched, negotiate so as to maximize their weighted joint surplus by a state-contingent choice of the real wage rate:

$$
\max _{\left\{w_{t}(j)\right\}}\left(W_{t}(j)-U_{t}(j)\right)^{\eta}\left(J_{t}(j)-V_{t}(j)\right)^{1-\eta} .
$$

The corresponding first order condition is

$$
\eta J_{t}(j) \underbrace{\frac{\partial\left[W_{t}(j)-U_{t}(j)\right]}{\partial w_{t}(j)}}_{:=\delta_{t}^{W, w}(j)}=\underbrace{-\frac{\partial\left[J_{t}(j)\right]}{\partial w_{t}(j)}}_{:=\delta_{t}^{F, w}(j)}(1-\eta)\left(W_{t}(j)-U_{t}(j)\right) .
$$

Since all firms are identical and each firm resets its wage every period, we can drop individual firm-worker pair indeces. The terms in (21) are

$$
\begin{gathered}
\delta_{t}^{F, w}=h_{t}+\phi_{L}\left[\left(w_{t}-w_{t-1}\right)+\beta(1-\rho)\left(w_{t+1 \mid t}-w_{t}\right)\right], \text { and } \\
\delta_{t}^{W, w}=\frac{h_{t}}{\alpha-1}\left\{\alpha-\frac{m r s_{t}}{w_{t}}\right\}, \text { where } m r s_{t}=\frac{\kappa_{h, t} h_{t}^{\phi}}{\lambda_{t}}
\end{gathered}
$$

is a worker's marginal rate of substitution between consumption and leisure.

${ }^{11}$ In our model, there is no beneficial motive for fixed wages. In particular, in some circumstances both workers and firms could be made better off by removing the real wage adjustment costs. We leave a more detailed exploration for future research. 
Labour Market Flows. Let $n_{t}$ be the measure of employed workers at the beginning of period $t$, before production takes place. A constant fraction $\rho$ of these are laid off just before work starts in $t$ and immediately join the pool of workers searching for a new job. The pool of workers searching during $t$ therefore is:

$$
u_{t}=1-(1-\rho) n_{t}
$$

The measure of newly matched workers, $m_{t}$, join the pool of employed workers in $t+1$, therefore aggregate employment evolves according to

$$
n_{t}=(1-\rho) n_{t-1}+m_{t-1}
$$

Here $n_{t}$ measures the beginning of period employment before job separation occurs and before production takes place. ${ }^{12}$ Note that thereby the measure of workers which actually produce in period $t$ is $(1-\rho) n_{t}$. This closes our description of the labor market and the intermediate good producing sector.

\subsubsection{Wholesale Sector}

Firms in the wholesale sector are distributed on the unit interval and indexed by $l \in(0,1)$. The homogenous intermediate good (see Section 2.2.1) is the only input into wholesale production, being traded in a competitive market for real price $x_{t}$ per unit. Wholesale firms produce a differentiated good $y_{t}(l)$ according to

$$
y_{t}(l)=y_{t}^{I}(l)
$$

where $y_{t}^{I}(l)$ denotes wholesale firm $i$ 's demand for the homogeneous intermediate good. Due to the linearity of the production function, $x_{t}$ coincides with wholesale firms' marginal cost. The typical firm sells its differentiated output in a monopolistically competitive market at nominal price $p_{t}(l)$. We follow Calvo (1983) in assuming that in each period a random fraction $\varphi \in(0,1)$ of firms cannot reoptimize their price. Following Christiano, Eichenbaum, and Evans (2005) and Smets and Wouters (2003), we assume that firms which cannot reoptimize their prices (partially)

\footnotetext{
12 End of period employment, say $\tilde{n}_{t}=(1-\rho) n_{t}$, evolves according to: $\tilde{n}_{t}=(1-\rho) \tilde{n}_{t-1}+(1-\rho) m_{t-1}$. This may look more familiar to some readers.
} 
index to the realized inflation rate. The degree of indexation is measured by parameter $\gamma_{p} \in(0,1)$. Wholesale firms face the demand function:

$$
y_{t}(l)=\left(\frac{p_{t}(l)}{P_{t}}\right)^{-\epsilon_{t}^{c p}} y_{t}, \epsilon_{t}^{c p}>1
$$

where $P_{t}$ is the economy wide price index and $y_{t}$ is an aggregate index of demand. The cost-push shock is modelled as a time-varying (own-price) elasticity of demand, $\epsilon_{t}^{c p}$. We assume that there are (cost-push) shocks, $\mu_{t}^{c p}$, to the elasticity of demand,

$$
\log \left(\epsilon_{t}^{c p}\right)=\log \left(\bar{\epsilon}^{c p}\right)+\mu_{t}^{c p}
$$

which are i.i.d. over time.

Wholesale firms which reoptimize their price in period $t$ face the problem of maximizing the value of their enterprise by choosing their sales price $p_{t}(l)$ taking into account the pricing frictions and their demand function:

$$
\max _{p_{t}(l)} E_{t}\left\{\sum_{j=0}^{\infty} \varphi^{j} \beta_{t, t+j}\left[\frac{p_{t}(l)}{P_{t+j}} \prod_{k=0}^{j-1}\left(\Pi_{t+k}^{\gamma_{p}} \bar{\Pi}^{1-\gamma_{p}}\right)-x_{t+j}\right] y_{t+j}(l)\right\}
$$

where $\Pi_{t+k}$ is the quarter on quarter gross inflation rate (from one quarter before to $t+k$ ) and $\bar{\Pi}$ marks the quarterly gross inflation rate in steady state. Their first order condition is:

$$
E_{t}\left\{\sum_{j=0}^{\infty} \varphi_{p}^{j} \beta_{t, t+j}\left[\frac{p_{t}(l)}{P_{t+j}}\left(1-\epsilon_{t+j}^{c p}\right) \prod_{k=0}^{j-1}\left(\Pi_{t+k}^{\gamma_{p}} \bar{\Pi}^{1-\gamma_{p}}\right)+\epsilon_{t+j}^{c p} x_{t+j}\right] y_{t+j}(l)\right\}=0 .
$$

Linearizing this first-order condition results in a standard New Keynesian Phillips curve. We turn to the final goods sector.

\subsubsection{Retail Firms}

Retail firms operate in perfectly competitive product markets. They buy differentiated wholesale goods and arrange them into a representative basket, producing the final consumption bundle $y_{t}$ 
according to

$$
y_{t}=\left[\int_{0}^{1} y_{t}(l)^{\frac{\epsilon_{t}^{c p}-1}{\epsilon_{t}^{c p}}} d l\right]^{\frac{\epsilon_{t}^{c p}}{\epsilon_{t}^{c p}-1}} .
$$

The cost-minimizing expenditure to produce one unit of the final consumption bundle is

$$
P_{t}=\left[\int_{0}^{1} p_{t}(l)^{1-\epsilon_{t}^{c p}} d l\right]^{\frac{1}{1-\epsilon_{t}^{c p}}} .
$$

Note that $P_{t}$ coincides with the consumer price index.

Closing the representation of production, market clearing in the markets for all goods requires that $^{13}$

$$
y_{t}=\left(1-u_{t}\right) y_{t}^{I}=\left(1-u_{t}\right) z_{t} h_{t}^{\alpha}=C_{t}
$$

Before we close the model by a description of monetary policy, we want to emphasize the role that our labor market characterization plays in the economy.

\subsection{The Wage-Inflation Channel in the Linearized Model}

In order to arrive at an empirically tractable version of the model, we linearize above equations around a zero-inflation, constant production steady state. While we defer a complete presentation of the linearized model to Appendix A, this section explains the determinants of aggregrate wages and the transmission from wages to inflation in our model. "Hats" denote percentage deviations from steady state while "bars" mark steady state values.

Equation (21) implicitly defines the "wage equation". While in its non-linear form the equation due to the wage adjustment costs cannot be brought into an accessible format, a lot can be learned from a linearized version. The wage equation (once linearized) can be rewritten as

$$
\widehat{w}_{t}=\gamma_{1} \widehat{m r} s_{t}+\gamma_{2}\left(\widehat{\kappa}_{t}-\widehat{\lambda}_{t}+\widehat{\theta}_{t}\right)-\left(\gamma_{2}+\gamma_{3}\right) \widehat{h}_{t}+\xi_{3} \widehat{\chi}_{t}-\xi_{2}\left(\widehat{\chi}_{t+1 \mid t}-\widehat{\chi}_{t}\right)
$$

\footnotetext{
${ }^{13}$ Here we use that wholesale production is linear in intermediate goods and that all intermediate goods firms have the same production level.
} 
Here

$$
\widehat{\chi}_{t}=\widehat{\delta}_{t}^{W, w}-\widehat{\delta}_{t}^{F, w}=\left[\frac{\partial}{\partial w_{t}}\left\{\eta\left(W_{t}-\widehat{\left.U_{t}\right)+(1}-\eta\right)\left(J_{t}-V_{t}\right)\right\}\right],
$$

where the final "hat" refers to the percentage deviation of the entire term in square brackets from steady state. $\hat{\chi}_{t}$ can consequently be interpreted as the approximate effect of a wage increase in a particular firm on total bargaining surplus of the firm-worker match. This leads to an intuitive interpretation of wage equation (31): Ceteris paribus the real wage rate will be the higher, the larger the worker's marginal rate of substitution of leisure for consumption, i.e. the less willing he is to work an additional instant of time. ${ }^{14}$ In addition, the wage rate will increase with rising real vacancy posting costs $\left(\widehat{\kappa}_{t}-\widehat{\lambda}_{t}\right)$ since these imply larger rents which can be extracted from the firm-worker relationship. A similar reasoning is valid for an increase in market tightness, $\theta_{t}$. Decreasing returns to labor mean that additional hours worked will turn ever less productive. The third factor might be interpreted to reflect this feature. The real wage rate will also be the higher the more total surplus increases with an increase in the wage (the $\widehat{\chi}_{t}$ factor). Finally, whenever $\widehat{\chi}_{t+1 \mid t}-\widehat{\chi}_{t}$ is positive, wage increases in the future are expected to have a more positive (less negative) effect on future total surplus than current wage increases have on the current surplus. This leads firms and workers to defer wage increases to a certain extent and, consequently, exerts a dampening effect on wages.

As regards the real wage rigidity, the effect of a marginal wage increase on total surplus, $\widehat{\chi}_{t}$, can be decomposed as

$$
\widehat{\chi}_{t}=\frac{\frac{\overline{m r s}}{\bar{w}}}{\frac{\overline{m r s}}{\bar{w}}-\alpha}\left(\widehat{m r s}_{t}-\widehat{w}_{t}\right)-\phi_{L} \frac{\bar{w}}{\bar{h}}\left[\left(\widehat{w}_{t}-\widehat{w}_{t-1}\right)-\beta(1-\rho)\left(\widehat{w}_{t+1 \mid t}-\widehat{w}_{t}\right)\right] .
$$

Thus the upward pressure on wages is increasing in the gap between the worker's subjective price of work and the market remuneration. ${ }^{15}$ In terms of wage rigidity, whenever $\phi_{L}>0$, the term

\footnotetext{
${ }^{14}$ As to the sign of parameters,
}

$$
\xi_{3}=\frac{\bar{\chi}}{1-\frac{\bar{\chi}}{\alpha}}\left(\frac{1}{\alpha}+\frac{\bar{\kappa} \bar{\theta}}{\overline{\lambda w h}}-\frac{\overline{m r s}}{\bar{w}(1+\phi)}-\frac{b}{\overline{w h}}\right) .
$$

This is strictly positive in our calibration. All the other parameters in (31) are strictly positive by definition (see Appendix A).

15 This assumes that $\frac{\overline{m r s}}{\bar{w}}-\alpha>0$, which is the case in our calibration. 
$\widehat{w}_{t}-\widehat{w}_{t-1}$ dampens both wage increases and wage reductions. This is done by increasing the total surplus from wage increases whenever there is a tendency to lower the wage rate and by reducing this effect whenever wage increases are imminent.

Wages in our model translate into inflation by increasing the cost of the intermediate good, $x_{t}$, via the intermediate good producer optimality condition (19), which translates into

$$
\widehat{x}_{t}=\widehat{w}_{t}-\left(\widehat{z}_{t}+(\alpha-1) \widehat{h}_{t}\right)
$$

Ceteris paribus, for the wholesale sector an increase in marginal cost, $x_{t}$, through an increase in real wages means an increase in inflation, $\widehat{\pi}_{t}$, via the New Keynesian Phillips curve

$$
\widehat{\pi}_{t}=\frac{\beta}{1+\beta \gamma_{p}} E_{t} \widehat{\pi}_{t+1}+\frac{\gamma_{p}}{1+\beta \gamma_{p}} \widehat{\pi}_{t-1}+\frac{(1-\varphi)(1-\varphi \beta)}{\varphi\left(1+\beta \gamma_{p}\right)}\left(\widehat{x}_{t}+\widehat{e}_{t}\right)
$$

where $\widehat{e}_{t}$ reflects the cost-push shock. ${ }^{16}$ All else equal, the impact of wages on marginal cost will be the larger the less pronounced inflation indexation (the closer $\gamma_{p}$ to zero) and the larger the fraction of wholesale firms allowed to update prices each period (the smaller $\varphi$ ).

\subsection{Monetary Policy}

The monetary authority is assumed to control the nominal one-period risk-free interest rate $R_{t}$. The empirical literature (see, e.g. Clarida, Gali, and Gertler, 1998 and 2000) finds that simple linearized generalized Taylor-type rules of the type

$$
\widehat{R}_{t}=\rho_{m} \widehat{R}_{t-1}+\left(1-\rho_{m}\right) \gamma_{\pi} E_{t}\left\{\widehat{\pi}_{t+1}-\widehat{\bar{\pi}}_{t}\right\}+\left(1-\rho_{m}\right) \gamma_{y} \widehat{y}_{t}
$$

represent a good representation of monetary policy. All parameters are non-negative. These rules state that the central bank sets interest rates in response to expected deviations of inflation from target $E_{t}\left\{\lambda_{t+1}-\bar{\pi}_{t}\right\}$ and in response to the output gap $y_{t} \cdot{ }^{17}$ In addition the central smoothes interest rates.

16 The Phillips curve is standard (see e.g. Smets and Wouters, 2003) and can be obtained by linearizing (27).

17 The output gap here is the percentage deviation of output from trend output. Potential output varies over the cycle and is hard to measure in real time. The deviation of output from trend thus is informationally less 
We allow for a serially correlated inflation target shock

$$
\log \left(\bar{\Pi}_{t}\right)=(1-\rho) \log (\bar{\Pi})+\rho \log \left(\bar{\Pi}_{t-1}\right)+\mu_{t}^{\bar{\Pi}},
$$

where $\mu_{t}^{\bar{\Pi}}$ is an i.i.d. shock.

\section{Calibration and Priors}

The literature has recently seen a surge of activity in estimating dynamic stochastic general equilibrium (DSGE) models by means of full information Bayesian techniques; see e.g. Schorfheide (2000), Smets and Wouters (2003), del Negro, Schorfheide, Smets, and Wouters (2004) and Lubik and Schorfheide (2005). The advantage of full information relative to limited information techniques is that model estimates will provide a complete characterization of the data generating process. In a Bayesian framework, through the prior density prior information (derived from earlier studies, from outside evidence or personal judgement) can be brought to bear on the estimation process in a consistent and transparent manner.

The decision of how much weight to place on different sources of prior information in the presence of possible identification problems ultimately depends on the goal of the analysis. We seek to strike a compromise in our calibration. We estimate those parameters which we think are most important for the problem at hand and fix the other parameters on the basis of outside evidence and estimates in the literature.

Fixed Parameters. We now turn to our calibration for the constant parameters.

- Elasticity of demand: $\bar{\epsilon}^{c p}=11$. Once the elasticity of output with respect to hours worked, $\alpha$, is fixed, the elasticity multiplies only the markup shock. It is therefore indistinguishable from the standard deviation of the markup shock. We set the own price elasticity of demand to 11 , a value implying a markup of $10 \%$ in the wholesale sector as in Trigari (2004) and many other papers. 
- Labor share: share=0.72. In steady state under right-to-manage the labor share is given by $^{18}$

$$
\text { share }=\frac{\epsilon^{c p}-1}{\epsilon^{c p}} \alpha .
$$

With an empirical estimate for the labor share and a calibration for $\epsilon^{c p}$, a value for $\alpha$ results. In our closed economy we decide to take the share of wage income in national income as the corresponding measure of share. Using our calibration for $\epsilon^{c p}=11$ this implies $\alpha=0.792$.

- Discount factor: $\beta=0.99$. This is the inverse of the mean ex-post real rate in our sample.

- Labor supply elasticity: $\phi=10$. The elasticity of intertemporal substitution of labor, $1 / \phi$, is small in most microeconomic studies (between 0 and 0.5 ). We follow the lead of Trigari (2004).

- Risk aversion: $\sigma=1$. We decide to use log-utility as is the prior mean in Smets and Wouters (2003).

- Separation rate: $\rho=0.08$. This is slightly higher than suggested by the evidence in Burda and Wyplosz (1994) accounting for the immediate separations of new matches prior to any production in our model. The latter feature in our model (i.e. "unsuccessful job interviews") is not reflected by the worker flow data.

- Searching workers: $\bar{u}=0.15$. In the data the mean ratio of employed persons to total labor force is 0.925 . Taking the value for the separation rate of $\rho=0.08$ from above, we arrive at a mean fraction of searching workers of $\bar{u}=1-(1-\bar{\rho}) \bar{n}=0.149$. The value of $\bar{u}$ is large in comparison with the official unemployment rate. In the model, however, $u$ is the pool of searching workers and should encompass workers who are not included in the official unemployment rate but searching for work (e.g., discouraged workers). For a thorough discussion see Yashiv (2006).

18 The labor share is share $=\frac{(1-\rho) n w h}{(1-\rho) n z h^{\alpha}}=x \alpha$, which uses $x \alpha z h^{\alpha-1}=w$ and $y=(1-\rho) n z h^{\alpha}$. With $x=\frac{\epsilon^{c p}-1}{\epsilon^{c p}}$ the desired expression follows. 
- Vacancies: $\bar{v}=0.1$. The number of vacancies empirically is hard to observe. We set the steady state number of vacancies to $\frac{2}{3}$ times the number of searching workers. This ensures that firms rather quickly find new workers, while workers have a harder time to find jobs.

- $\eta=0.2 . \eta$ is a key determinant of the share of wages in total surplus (yet not in profits) and hence a determinant between the gap between unemployment benefit and wage income. We calibrate the bargaining power parameter so as to achieve a reasonable replacement rate, $\left(\frac{b}{w h}=0.5\right)$. In line with the recent literature, a relatively low bargaining power of workers results.

- No serial correlation of the cost-push and the preference (consumption demand) shock. Abstracting from serial correlation in the cost-push shock is standard in the literature; see e.g. Smets and Wouters (2003). Wherever possible our prior is to use economic theory to explain the data instead of using serial correlation in shock processes. In our model, the preference shock will strongly drive consumption. We therefore cannot identify whether the autoregressive pattern in consumption results from an autocorrelated consumption preference shock or from habit persistence in consumption. Following the guidance of economic theory we let habit persistence explain consumption persistence. On top, this also ensures the typical hump-shaped response of consumption/output to a monetary policy shock.

- Summing up, these values imply a steady-state probability of finding a worker of $\bar{q}=0.74$. The probability of finding a job is $\bar{s}=0.5$. This implies that an average unemployment spell lasts for 2 quarters. Our calibration also implies that structural obstructions to hiring/setting up a firm account for roughly one and a half quarters of production, captured by real vacancy posting costs $\bar{\kappa} / \overline{\lambda y}=1.5 .^{19}$

Table 1 summarizes the values of the fixed parameters.

\footnotetext{
19 The large value of vacancy posting costs is needed to offset the considerable ex post/per period profits in the intermediate goods sector originating from the decreasing returns to scale in production. Note that $\bar{\kappa}_{h}$ is not needed in order to estimate the model and fix the steady state ratios.
} 
Table 1: Fixed Parameters

\begin{tabular}{lccccccccc}
\hline \hline Parameter & $\bar{\epsilon}^{c p}$ & $\alpha$ & $\beta$ & $\phi$ & $\sigma$ & $\rho$ & $\bar{u}$ & $\bar{v}$ & $\eta$ \\
\hline Value & 11 & 0.792 & 0.99 & 10 & 1 & 0.08 & 0.15 & 0.1 & 0.2 \\
\hline \hline
\end{tabular}

Notes: values of parameters which are kept fixed in the subsequent estimation.

Priors for Estimated Parameters. We opt to model priors for almost all parameters as normally distributed with tight enough prior standard deviations and truncated to reflect the support considerations where necessary. We follow the literature in modelling the standard deviation of innovations as inverse-gamma with fat tails as we lack prior information on those variances. We assume that all marginal priors are independent.

- Priors for the Taylor rule. As in Taylor's (1993) original suggestion for the U.S., we set the mean of $\gamma_{\pi}$ to 1.5 and the mean of $\gamma_{y}$ to $0.5 / 4 .{ }^{20}$ We allow for wide standard deviations of 0.3 for both parameters. Woodford, among others, has repeatedly emphasized that inertia is a property of optimal monetary policy (see e.g. Woodford, 2003). We set a prior mean for the indexation parameter, $\rho_{m}$, to 0.75 and a standard deviation of 0.05 . These values are very similar to those estimated by Clarida, Gali, and Gertler (1998) on German data. ${ }^{21}$

- Habit persistence, $h_{c}$. Consumption habit has a prior mean of 0.85 , which is higher than the value of roughly 0.5 commonly found in the literature (cp. e.g. Smets and Wouters, 2003). In Smets and Wouters (2003) yet, for instance, the autocorrelation of the preference shock (estimated to be 0.9 ) is allowed to partly take the burden of explaining the serial correlation of consumption.

- Price stickiness, $\varphi$. Our prior mean of 0.9 assumes that $10 \%$ of firms update their prices each quarter, which is the posterior mode estimate of Smets and Wouters (2003) for the euro area. The implication that prices are sticky for an average of 10 quarters is tenable for the

${ }^{20}$ We deviate from Taylor's (1993) suggestion by modelling the response to inflation as being preemptive, and in modelling interest rate inertia.

21 They use monthly data from 1979 to 1993 and estimate

$$
\widehat{r}_{t}=0.75 \widehat{r}_{t-1}+(1-0.75)\left[1.31 / 4 E_{t}\left\{\widehat{\pi}_{t+4}^{y o y}\right\}+0.25 / 4 \widehat{y}_{t}\right]
$$

where $\widehat{\pi}_{t}^{\text {yoy }}:=\widehat{\pi}_{t}+\widehat{\pi}_{t-1}+\widehat{\pi}_{t-2}+\widehat{\pi}_{t-3}$ marks annual (year-on-year) inflation. The persistence coefficient is adjusted $\left(\rho=0.91^{3}\right)$ to match our quarterly frequency. 
German economy. See Hoffmann and Kurz-Kim (2004) for evidence.We impose a standard deviation of 0.05 .

- Price indexation, $\gamma_{p}$. Our model allows for persistent marginal costs through persistent technology shocks and additionally through persistence of wages. We therefore set mean price indexation to the rather small value of 0.3 . This is in line with the euro area evidence reported in Gali, Gertler, and López-Salido (2001). For comparison, Smets and Wouters (2003) estimate a posterior mode value of 0.4 which given their prior corresponds to a value more than two standard deviations below their prior mean. We allow for a wide standard deviation of 0.1 in order to accommodate other values of $\gamma_{p}$.

- Weight on the number of job-seekers in matching, $\sigma_{2}$. We set a mean of 0.4 and take a prior standard deviation of 0.05. Burda and Wyplosz (1994) estimate a value of $\sigma_{2}=0.68$. The lower value in our calibration reflects our prior that in the last decade in Germany the unemployment rate will not have been the main driving force behind new matches.

- Wage indexation, $\phi_{L}^{\text {new }}$. The mean value of 0.25 was chosen on the basis of prior experimentation with the model. To the best of our knowledge no independent evidence exists that would help to set this parameter. We allow for a (in our view and experience) wide standard deviation of 0.1 on our prior.

Next we turn to our priors for the serial correlation of the shocks, which are important for determining the system's dynamics. Some of the serial correlation parameters are at the boundary of values suggested in the literature. This is largely due to our modelling strategy that we try to be as parsimonious as possible with respect to introducing shocks. We see this as a virtue of our approach.

- Shock to inflation target, $\rho_{e \bar{\pi}}$. We choose a prior mean of 0.3. Smets and Wouters (2003) allow for two "monetary policy shocks": one persistent shock to the inflation target and additionally one serially uncorrelated innovation. Our prior tries to strike a compromise but allows for a wide standard deviation of 0.2 . 
- Shock to vacancy posting costs, $\rho_{e \kappa}$. We set a mean of 0.7 . Vacancy posting costs are a catch-all for impediments to setting up firms/hiring workers. As such, our prior dictates that these ought to be persistent. We choose a prior standard deviation of 0.1.

- Technology shock: $\rho_{e z}$. We impose a prior mean of 0.9 for the technology shock that is in line with the values conventionally used in the RBC literature for quarterly data. We set a standard deviation of 0.025 .

- Shock to disutility of work: $\rho_{e \kappa h}$. This shock will loosen the connection between the very persistent technology shock and wages. Smets and Wouters (2003) assume that labor supply shocks themselves are very persistent. However, they on top of this also introduce an iid "wage mark-up shock". Economically, a prior mean of 0.3 on the serial correlation of the disutility of work shock is reasonable. We allow for a standard deviation of 0.1 in our prior.

- Cost-push and demand preference shocks are assumed to be i.i.d.

All priors for the standard deviations follow inverse gamma distributions. The exception being the innovation to the disutility of work shock: there we use a tighter normal prior to explicitly restrict the support of this innovation.

Observable Variables. Much of the recent debate in the labor market literature (see e.g. Hall, 2005, and Shimer, 2005) has focused on the variability of vacancies. Hall (2005), in an efficient bargaining framework, shows that if the labor share is sufficiently large and the wage bill does not fluctuate much, profits (and the profit share) fluctuate considerably. This in turn induces the number of vacancies to fluctuate as much as in the data - a fact the matching model had been criticized of not being able to match. In a right-to-manage framework, up to first order, the labor share is determined by technology, not by bargaining power (and, besides, is constant over time). We therefore are not able to exactly match the volatility of vacancies in the data. As emphasized by Christoffel and Linzert (2005), however, right-to-manage bargaining introduces a direct channel from wages to inflation. We weigh the advantages of both bargaining schemes and decide to pursue right-to-manage here. Consequently we do not treat vacancies as a variable which we want to match in our estimation. 
Hours worked are imprecisely measured in the German national statistics. The specific choice of the time-series for hours would have influenced our results to a considerable extent with not much theoretical guidance for the choice of a particular series of the many which are available. We therefore decide not to treat hours worked as one of our observable variables but to limit ourselves to fitting the time-series of consumption, employment, real wages, (consumer price) inflation and nominal interest rates.

\section{Estimation Results}

In our empirical study, we employ quarterly German data from 1977:1 to 2004:2; see Appendix B for details on the sources and properties of the data. Thirty of these observations are used for presampling so that the observation sample starts in 1984:3.

Table 2 shows our estimates of the posterior mode for the model parameters. Further estimation statistics (posterior mean, median and coverage intervals) are delegated to Appendix C, Table 10. The Taylor rule estimates are in line with the evidence by Clarida, Gali, and Gertler (1998). Our estimate of habit persistence, $h_{c}=0.83$, is still somewhat larger than usually found in the literature but below our prior mean. This may be attributed to the fact that we do not allow for serially correlated demand shocks. This Calvo probability, $\varphi=0.92$, is larger than the prior mean. The degree of stickiness seems to be too high, even in light of German micro pricing studies. Bringing this estimate down to reasonable numbers recently has been the scope of a growing literature; see Altig, Christiano, Eichenbaum, and Linde (2005), Eichenbaum and Fisher (2003) and Kuester (2006), for instance. We find a low degree of price indexation, $\gamma_{p}=0.26$. Finally, the weight on unemployment in the matching process is estimated to be well below half, $\sigma_{2}=0.31$. New matches in the German data according to our model estimates are driven by vacancies rather than by the pool of unemployed workers in contrast to the estimates of Burda and Wyplosz (1994) until 1991.

Turning to shock persistence, our results seem in line with the literature. Worth mentioning is that labor market friction shocks (vacancy posting shocks) are estimated to be less persistent than the prior mean, $\rho_{\kappa}=0.6$. The innovation to the disutility of work, $\mu^{\kappa_{h}}$, does not match well with 
Table 2: Estimated Parameters at the Posterior Mode

\begin{tabular}{|c|c|c|c|c|c|c|}
\hline \multirow[t]{2}{*}{ Parameter } & \multicolumn{3}{|c|}{ prior } & \multicolumn{2}{|c|}{ posterior } & \multirow[t]{2}{*}{ "t-stat" } \\
\hline & mean & std & distr. & mode & std & \\
\hline \multicolumn{7}{|c|}{ Parameters of Structural Model } \\
\hline$\rho_{m}$ & 0.750 & 0.0500 & norm & 0.7852 & 0.0347 & 22.6258 \\
\hline$\gamma_{\pi}$ & 1.500 & 0.3000 & norm & 1.4020 & 0.2396 & 5.8514 \\
\hline$\gamma_{y}$ & 0.125 & 0.3000 & norm & 0.1907 & 0.0579 & 3.2915 \\
\hline$h_{c}$ & 0.850 & 0.0500 & norm & 0.8295 & 0.0324 & 25.5776 \\
\hline$\varphi$ & 0.900 & 0.0500 & norm & 0.9242 & 0.0138 & 67.1596 \\
\hline$\gamma_{p}$ & 0.300 & 0.1000 & norm & 0.2638 & 0.0691 & 3.8164 \\
\hline$\sigma_{2}$ & 0.400 & 0.0500 & norm & 0.3113 & 0.0505 & 6.1666 \\
\hline$\phi_{L}^{\text {new }}$ & 0.250 & 0.1000 & norm & 0.3622 & 0.0515 & 7.0392 \\
\hline \multicolumn{7}{|c|}{ Serial Correlation of Shocks } \\
\hline$\rho_{\bar{\pi}}$ & 0.300 & 0.2000 & norm & 0.3554 & 0.0982 & 3.6178 \\
\hline$\rho_{\kappa}$ & 0.700 & 0.1000 & norm & 0.5973 & 0.0630 & 9.4833 \\
\hline$\rho_{z}$ & 0.900 & 0.0250 & norm & 0.9339 & 0.0251 & 37.1918 \\
\hline$\rho_{\kappa_{h}}$ & 0.300 & 0.1000 & norm & 0.2040 & 0.0845 & 2.4139 \\
\hline \multicolumn{7}{|c|}{ Standard Deviation of Innovations } \\
\hline$\mu^{\bar{\pi}}$ & 0.007 & Inf & invg & 0.0028 & 0.0006 & 4.8168 \\
\hline$\mu^{\text {pref }}$ & 0.100 & Inf & invg & 0.0683 & 0.0130 & 5.2528 \\
\hline$\mu^{z}$ & 0.006 & Inf & invg & 0.0042 & 0.0012 & 3.6615 \\
\hline$\mu^{\text {cost-push }}$ & 0.001 & Inf & invg & 0.0029 & 0.0003 & 11.1078 \\
\hline$\mu^{\kappa}$ & 0.010 & Inf & invg & 0.0253 & 0.0062 & 4.1023 \\
\hline$\mu^{\kappa_{h}}$ & 0.200 & 0.1000 & norm & 0.4350 & 0.0564 & 7.7181 \\
\hline
\end{tabular}

Notes: Estimates of the posterior mode. The standard deviation is obtained by a Gaussian approximation at the posterior mode. "t-stat" refers to the mode estimate divided by the posterior marginal standard deviation. Nota bene: The underlying calibration is such that $\bar{q}=0.7391, \bar{s}=0.4928, \bar{w} \bar{h} / \bar{y}=\alpha=0.72, \bar{\kappa} /(\bar{\lambda} \bar{y})=1.4771$, $b /(\bar{w} \bar{h})=0.5, \bar{u}=0.15$ and $\bar{v}=0.1$. We define $\phi_{L}^{\text {new }}=\frac{\bar{w}}{\bar{h}} \phi_{L} / 1000$ for better readability. 
the prior. Its posterior value is 0.44 , well above its prior mean. The remaining posterior mode estimates of innovation standard deviation appear to be reasonable.

As a measure of matching data properties, Table 3 reports how well the standard deviations of the endogenous variables in our model match with the time-series evidence. To that aim, we

Table 3: Model Second Moments Relative to Data

\begin{tabular}{lccccc}
\hline \hline Variable & RMSE (model) & RMSE (VAR) & std (model) & std (data) & std (VAR) \\
\hline$\widehat{y}_{t}$ & 1.09 & 0.96 & 1.67 & 1.73 & 1.66 \\
$\widehat{r}_{t}$ & 0.09 & 0.08 & 0.36 & 0.44 & 0.37 \\
$\widehat{\pi}_{t}^{a n n}$ & 0.37 & 0.40 & 1.47 & 1.32 & 1.10 \\
$\widehat{n}_{t}$ & 0.43 & 0.38 & 0.85 & 1.09 & 1.03 \\
$\widehat{w}_{t}$ & 0.62 & 0.58 & 2.39 & 2.23 & 1.65 \\
\hline \hline
\end{tabular}

Notes: All entries have been multiplied by 100. The table compares the root mean squared forecast error of the model evaluated at the posterior mode (second column) to the root mean squared forecast errors resulting from a $\operatorname{VAR}(2)$ in the sample 1984:3 - 2004:2 (third column). The fourth to sixth column compare the standard deviations implied by the model to those taken directly from the data and those taken from an auxiliary $\operatorname{VAR}(2)$. Nota bene: standard deviation of hours (very dependent on the choice of the data series): 0.0210 (model) vs. 0.05328(data); standard deviation of vacancies: 0.0817 (model) vs. 0.3016 (data).

compare the model standard deviations to those taken directly from the data and to those taken from an auxiliary $\operatorname{VAR}(2)$ model. Overall, our model seems to fit the second moments of the data rather well. When it comes to comparing root mean squared forecast errors, only the consumption equation falls behind a $\operatorname{VAR}(2)$ in terms of forecast performance. That the model explains the data well is corroborated also by the marginal data densities displayed in Table 4 with the model consistently outperforming Bayesian VARs. Marginal data densities are used to judge the posterior odds of one model against another. We assess our structural model against VARs with flat priors. The larger the marginal data density of our model relative to the benchmark VAR, the better the posterior odds for our structural model; see e.g. Lubik and Schorfheide (2005) for an accessible exposition.

Table 4: Log Marginal Data Densities

\begin{tabular}{lccccc}
\hline \hline \multicolumn{2}{c}{ BVAR(1) } & \multicolumn{2}{c}{ BVAR(2) } & \multicolumn{2}{c}{ Model } \\
true & Laplace & true & Laplace & Laplace & Harm. Mean \\
\hline 1586.43 & 1585.66 & 1576.32 & 1574.25 & 1609.83 & 1609.86 \\
\hline \hline
\end{tabular}

Notes: Marginal data density of Bayesian VARs with one and two lags under flat priors, using the Laplace approximation and the exact formula each. The model marginal data density is computed using the Laplace approximation and the modified harmonic mean. 
Table 5 illustrates that the persistence of real wages and inflation implied by the model is very similar to the persistence found in the data (compare also Table 8 in Appendix E).

Table 5: Persistence Measures

\begin{tabular}{lccccc}
\hline \hline Variable & $\beta_{1}$ & $\beta_{1}+\beta_{2}$ & $\beta_{1}+\ldots+\beta_{3}$ & $\beta_{1}+\ldots+\beta_{4}$ & $\beta_{1}+\ldots+\beta_{5}$ \\
\hline$\widehat{w}_{t}$ & $0.94(0.93)$ & $0.92(0.92)$ & $0.92(0.91)$ & $0.92(0.93)$ & $0.92(0.92)$ \\
$\widehat{\pi}_{t}^{\text {ann }}$ & $0.93(0.93)$ & $0.90(0.92)$ & $0.89(0.91)$ & $0.89(0.89)$ & $0.93(0.91)$ \\
\hline \hline
\end{tabular}

Notes: Shown is the sum of up to the first five regression coefficients when regressing the relevant variable on its own lags (evaluated at the posterior mode). Regression coefficients are based on the estimated model at the posterior mode. In brackets are the values measured in the data.

We delegate a further measure of fit to Appendix D: Figure 7 in that appendix reports model cross-correlations and compares those to the cross-correlations measured in the data. By and large, we conclude, the model does a good job at fitting the data. We next turn to the propagation mechanism of shocks and ultimately to the policy considerations.

\section{The Labor Market and the Dynamics of the Economy}

In this section, we analyze the dynamics of the estimated model. Towards that aim, we present empirical impulse response functions as well as forecast error variance decompositions. In particular, we investigate the specific role of the labor market for the model's dynamics. Additionally, we will present counterfactual scenarios illustrating the dynamics of the economy in different labor market regimes.

In a first step, we are particularly interested in how a monetary policy shock is transmitted in the presence of a rigid non-Walrasian labor market. An increase in the inflation target in our model corresponds to the central bank decreasing its key interest rate (see the solid line in Figure 1). The lowered rate reduces savings and increases household consumption. The increased demand in turn requires additional labor input. Due to the rigidities in the labor market the number of employed workers cannot be increased instantly. ${ }^{22}$ Hence labor adjustment is initially implemented via an increase of hours worked per employee. In the following, for brevity the term "profits" refers

${ }^{22}$ Although this would be beneficial from a welfare perspective due to decreasing returns to labor. 
only to profits in the intermediate goods sector, i.e. in the sector where all labor market activity takes place. With "profits" we mean the value of period profits current and future accruing to a single firm which operates in the intermediate goods sector in $t$. We thus use the term "profits" as synonymous to "market value of a firm in the intermediate goods sector" in $t$, denoted by $J_{t}$ in equation (8). We explicitly denote by "period profits" the period profits of a single firm in $t$, labelled $\psi_{t}$ in equation (18). The rise in demand following the increase of the inflation target boosts expected profits. Vacancy posting increases until expected profits equal the posting costs. In anticipation of higher profits the value of an employment relation increases and workers aspire higher wages. Firms' marginal cost of production increase with higher wage rates implying higher prices and higher inflation (see Figure 1).

Figure 1 also shows a counterfactual exercise illustrating the effect of wage rigidity. ${ }^{23}$ We compare the response to an inflation target shock in the estimated model with the response in a model assuming flexible wages. ${ }^{24}$ In the right-to-manage wage bargaining model, period profits and wages are tightly positively linked, cp. (33) in Appendix A. Note also that real wage increases are passed on one for one to suppliers of wholesale goods. With full wage flexibility, real wages increase more pronouncedly. Since wage costs are passed on to the wholesale sector, period profits of firms which operate in the intermediate goods market can increase more sharply after a monetary policy shock even though the wage increase is more pronounced than under rigid wages. This contrasts with the efficient-bargaining model used e.g. in Hall (2005). In the efficient wage bargaining model, rigid wages would translate into more fluctuation in profits than flexible wages. In our model, the increase of marginal costs in turn triggers a stronger response of inflation compared to the benchmark model with rigid wages. Therefore, introducing wage rigidity in the right-to-manage model smoothes wages as well as marginal cost so that the wage induced inertia in marginal costs translates into more persistent inflation via the New Keynesian Phillips curve similar to the mechanism mentioned in Christiano, Eichenbaum, and Evans (2005). In terms of the response of unemployment, more flexible wages yield a stronger fall of unemployment. In

\footnotetext{
${ }^{23}$ A detailed description of all the counterfactual exercises can be found in Appendix E.

24 The red dotted line marked by triangles in Figure 1 shows the impulse responses when wage rigidity is eliminated. Towards that aim, we set the wage adjustment cost parameter $\phi_{L}^{\text {new }}$ to zero.
} 
Figure 1: Impulse Responses to 1\% Inflation Target Shock.

Consumption

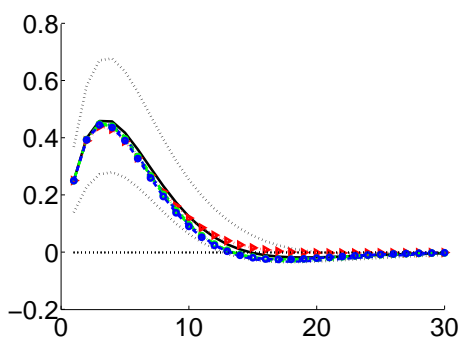

Unemployment

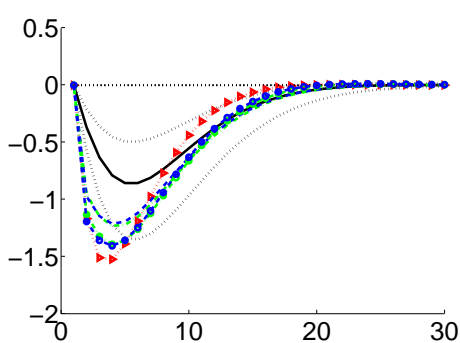

Hours per Worker

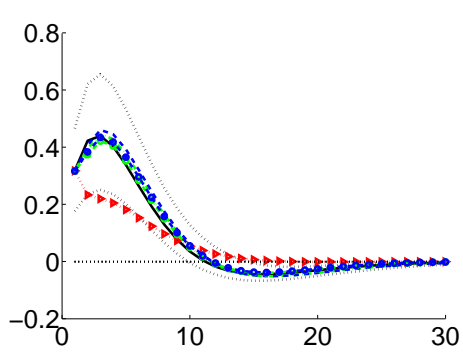

Quarterly Inflation

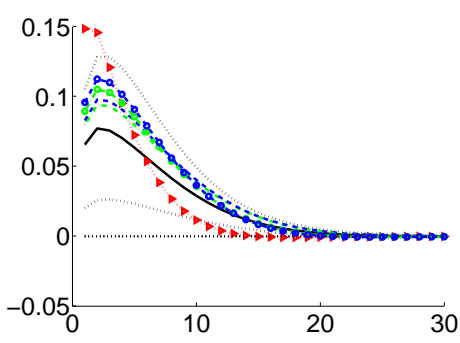

Vacancies

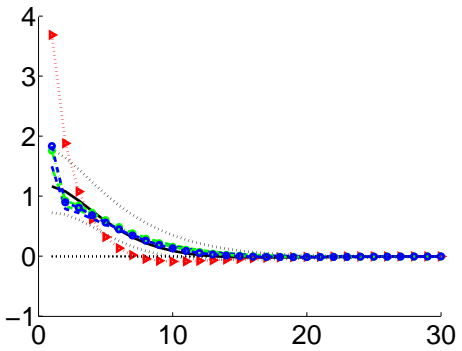

Marginal Cost

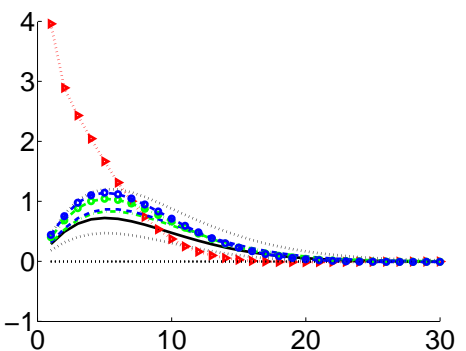

Nominal Rate

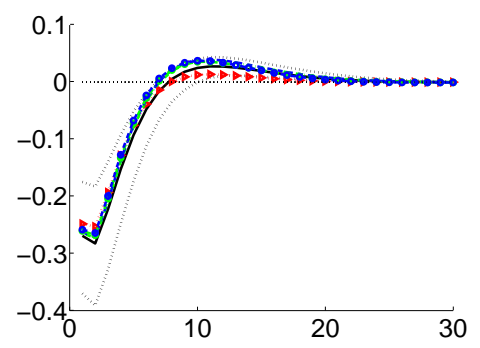

Period Profits

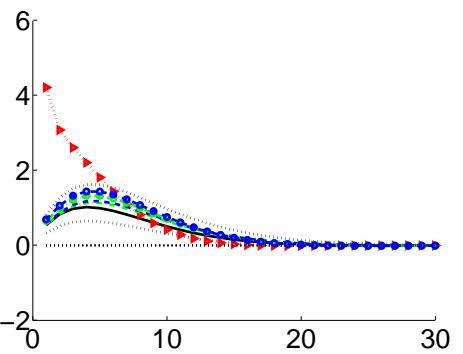

Real Wage Rate

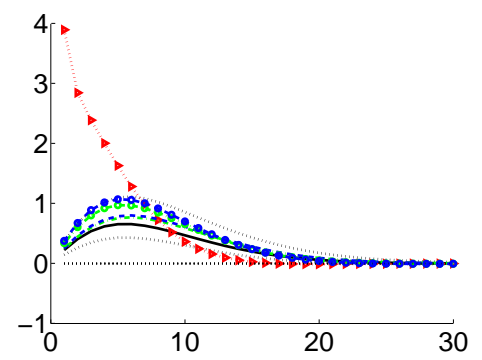

Notes: The figures show percentage responses (1 in the plots corresponds to 1\%) of endogenous variables to a one percent increase in the inflation target. The black solid line marks the estimated model (at the posterior mode). Black dotted lines mark 95\% confidence intervals (using 100.000 draws from the posterior distribution). The red line marked by triangles shows the case of no wage rigidity. The remaining blue dashed lines and the green dashed-dotted lines correspond to the counterfactual flexible labor market experiments described in more detail in Appendix E. Nb: an increase of unemployment of 1 in the plot means that the unemployment rate increases by $1 \%$, say from 0.15 to 0.1515 ; not by one percentage point! 
addition, unemployment appears to be somewhat less persistent than under a regime of rigid wages. ${ }^{25}$

Additionally, Figure 1 shows another counterfactual exercise. We compare responses of variables to an inflation target shock in the benchmark model to the one under a flexible labor market regime (see the dashed blue and dashed-dotted green lines in the figure). The labor market is less rigid in the following sense: We assume that all searching workers immediately are matched with a new employer in steady state, which corresponds to an abundance of firms in the market. ${ }^{26}$ We do, however, retain the wage rigidity. Appendix E describes in detail how we implement this flexible labor market scenario. An increase in the inflation target decreases the real interest rate leading to an increase in consumption. Hence period profits rise and vacancies increase accordingly. In a more flexible labor market regime, labor market tightness is affected more by movements in unemployment. This in turn translates into larger movements in wages and also inflation than in the rigid baseline. Therefore, we conclude that more rigid labor markets, especially when rigidities lie on the wage side, lead to more persistent movements in inflation. This implies that the transmission mechanism of monetary policy is influenced by the degree of rigidities in the labor market - and that the latter are of first-order importance for the way monetary policy needs to be conducted.

In a second step, we look directly at shocks originating in the labor market. Towards that aim, we proxy labor market impediments by the cost of vacancy posting. We analyze how a shock to vacancy posting affects the nominal and real variables in our model (see the solid black line in Figure 2). In our simulations, a vacancy posting cost shock increases the cost of posting a vacancy by $1 \%$. Vacancy posting activity decreases and the job destruction rate remains constant by assumption. Hence unemployment increases. Hours worked need to increase to satisfy consumption demand. Consumption itself is affected only slightly due to the estimate of strong habits and the assumption of income pooling. Rising job creation costs mean higher barriers to entry and thus higher rents from an existing employment relationship in the intermediate goods sector. This

${ }^{25}$ Notice that due to income pooling the labor market dynamics do not translate into changes in the behavior of consumption.

26 There will still be unemployment, however, since workers continue to start being productive only a period after having been matched. 
leads to both a rise in wages and in the period profits of each firm which already operates in the market, and ultimately to a rise in inflation.

Figure 2 also shows the response of the variables to a vacancy posting cost shock under a flexible wage regime. An increase in vacancy posting costs depresses vacancy postings as before. Period profits of operating firms rise to a greater extent than in the baseline. Higher period profits in the intermediate goods sector in turn lead to higher wages and higher marginal costs which translates into an increased response of inflation. Increased profits of incumbent firms also mean that vacancies experience a smaller drop and unemployment rises by less than in the benchmark.

Closely watching labor market developments could be important for monetary policy makers if these developments ultimately have a non-negligible effect on inflation and consumption, and on potential output, and if the traditional New Keynesian variables are not sufficient statistics in this respect. While a welfare-theoretic exploration is beyond the scope of this paper the following provides a first, and admittedly coarse, look at the importance of labor market shocks. The variance decomposition in Table 6 shows how much of the forecast error variance in each variable at different forecast horizons is due to a specific set of innovations. Corroborating the variance decomposition evidence in Table 6, we report actual error decompositions (after running the Kalman smoother) at business cycle frequencies in Figure 3.

The vacancy posting cost shock is the key driving force of employment ( $87 \%$ in the short-run and $63 \%$ in the long run) and vacancies (roughly $80 \%$ in the short and long-run). It is also an important determinant for wages, hours worked and marginal cost (roughly $10 \%$ to $15 \%$ in the short and long run) but with not enough transmission to let it matter for inflation or consumption. As is apparent from Table 6 less than 5 percent of the variation of inflation, output and interest rates is driven by the labor market shock. This result holds at all frequencies. We can conclude that the impact of shocks to vacancy posting on the "traditional" New Keynesian nominal and real variables of the model is rather limited.

Finally, still in Table 6 and Figure 3, we take a closer look at the labor market itself. We see that besides the vacancy posting cost shock and the disutility of work shock, labor market variables are especially influenced by technology and demand shocks. In contrast, the inflation 
Figure 2: Impulse Responses to 1\% Vacancy Posting Cost Shock.

Consumption

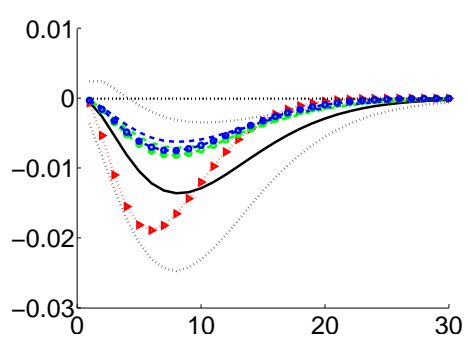

Unemployment

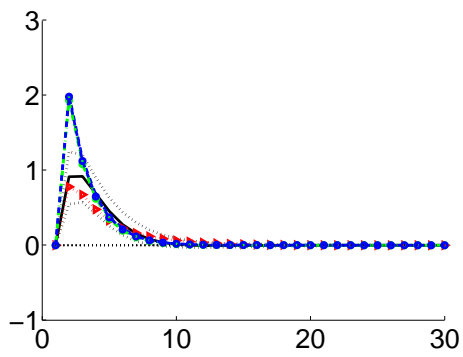

Hours per Worker

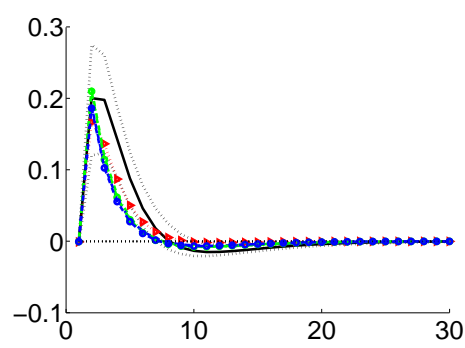

Quarterly Inflation

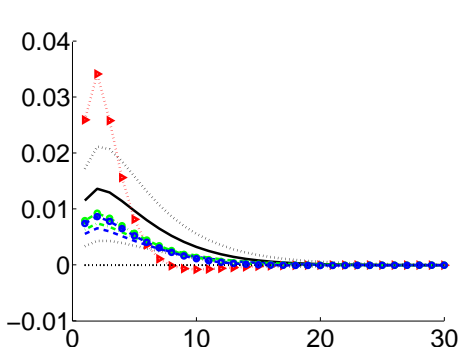

Vacancies

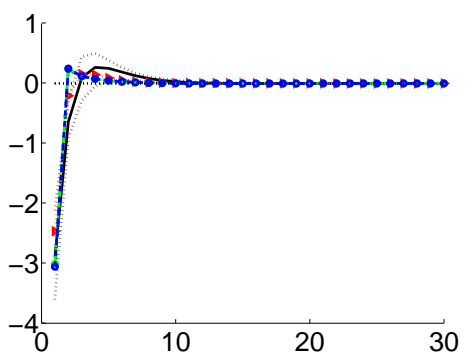

Marginal Cost

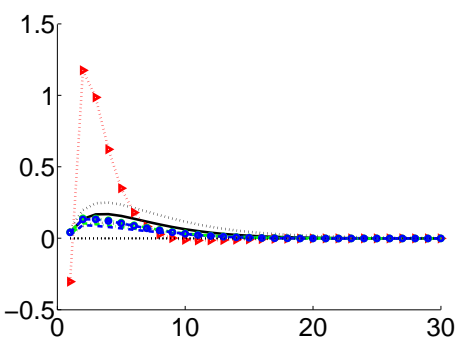

Nominal Rate

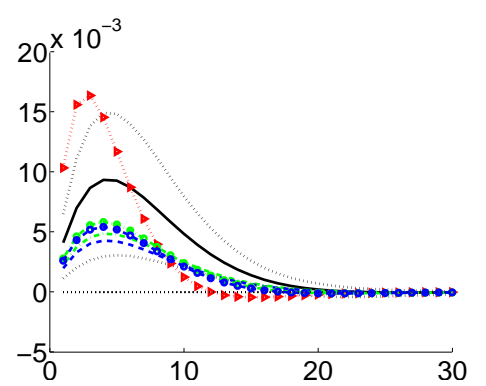

Period Profits

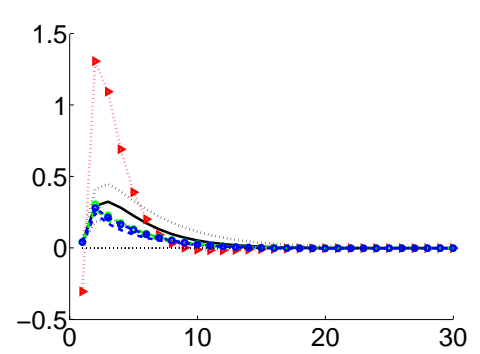

Real Wage Rate

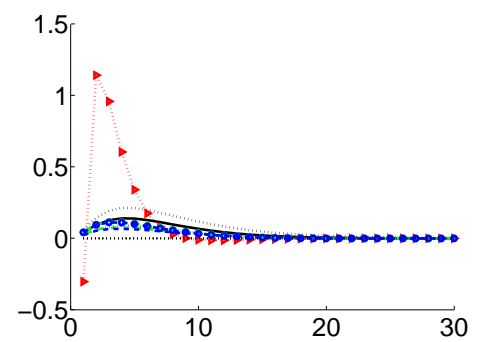

Notes: The graphs show percentage responses (1 in the plots corresponds to $1 \%$ ) of endogenous variables to a one percent increase in vacancy posting costs. The black solid line marks the estimated model (at the posterior mode). Black dotted lines mark 95\% confidence intervals (using 100.000 draws from the posterior distribution). The red line marked by triangles shows the case of no wage rigidity. The remaining blue dashed lines and the green dashed-dotted lines correspond to the counterfactual flexible labor market experiments described in more detail in Appendix E. Nb: an increase of unemployment of 1 in the plot means that the unemployment rate increases by $1 \%$, say from 0.15 to 0.1515 ; not by one percentage point! 
Table 6: Forecast Error Variance Decomposition

\begin{tabular}{|c|c|c|c|c|c|c|}
\hline Variable & target & demand pref. & technology & cost-push & vacancy & disutility lab. \\
\hline \multicolumn{7}{|c|}{ Horizon 2} \\
\hline$\widehat{y}_{t}$ & 00.89 & 99.08 & 00.02 & 00.01 & 00.00 & 00.00 \\
\hline$\widehat{r}_{t}$ & 50.39 & 28.57 & 12.41 & 06.25 & 01.24 & 01.15 \\
\hline$\widehat{\pi}_{t}^{a n n}$ & 00.35 & 01.50 & 08.68 & 87.65 & 00.86 & 00.96 \\
\hline$\widehat{n}_{t}$ & 00.19 & 08.62 & 03.69 & 00.00 & 86.52 & 00.99 \\
\hline$\widehat{w}_{t}$ & 01.46 & 24.31 & 07.05 & 00.04 & 05.83 & 61.31 \\
\hline$\widehat{x}_{t}$ & 01.02 & 28.36 & 37.18 & 00.02 & 05.02 & 28.40 \\
\hline$\widehat{h}_{t}$ & 00.62 & 79.25 & 12.70 & 00.00 & 07.32 & 00.11 \\
\hline$\widehat{v}_{t}$ & 00.32 & 09.87 & 04.74 & 00.01 & 83.90 & 01.17 \\
\hline \multicolumn{7}{|c|}{ Horizon 10} \\
\hline$\widehat{y}_{t}$ & 03.25 & 93.59 & 02.72 & 00.13 & 00.18 & 00.13 \\
\hline$\widehat{r}_{t}$ & 17.55 & 37.84 & 38.21 & 02.14 & 02.50 & 01.77 \\
\hline$\widehat{\pi}_{t}^{a n n}$ & 01.60 & 04.34 & 43.01 & 45.41 & 03.16 & 02.48 \\
\hline$\widehat{n}_{t}$ & 01.62 & 15.80 & 14.53 & 00.07 & 65.97 & 02.02 \\
\hline$\widehat{w}_{t}$ & 04.97 & 30.03 & 16.81 & 00.24 & 15.20 & 32.74 \\
\hline$\widehat{x}_{t}$ & 03.26 & 24.15 & 44.33 & 00.16 & 11.02 & 17.08 \\
\hline$\widehat{h}_{t}$ & 01.48 & 69.45 & 13.11 & 00.05 & 14.90 & 01.03 \\
\hline$\widehat{v}_{t}$ & 00.57 & 09.99 & 06.13 & 00.02 & 82.09 & 01.20 \\
\hline \multicolumn{7}{|c|}{ Horizon 40} \\
\hline$\widehat{y}_{t}$ & 03.12 & 88.64 & 07.65 & 00.13 & 00.28 & 00.19 \\
\hline$\widehat{r}_{t}$ & 14.46 & 31.99 & 48.10 & 01.75 & 02.19 & 01.51 \\
\hline$\widehat{\pi}_{t}^{a n n}$ & 01.47 & 03.68 & 52.29 & 37.67 & 02.76 & 02.12 \\
\hline$\widehat{n}_{t}$ & 01.75 & 15.19 & 18.17 & 00.09 & 62.85 & 01.96 \\
\hline$\widehat{w}_{t}$ & 05.39 & 28.33 & 20.77 & 00.28 & 14.83 & 30.41 \\
\hline$\widehat{x}_{t}$ & 03.26 & 21.37 & 50.16 & 00.16 & 10.00 & 15.04 \\
\hline$\widehat{h}_{t}$ & 01.49 & 69.33 & 13.05 & 00.05 & 14.95 & 01.14 \\
\hline$\widehat{v}_{t}$ & 00.57 & 09.97 & 06.38 & 00.02 & 81.85 & 01.20 \\
\hline
\end{tabular}

Notes: Forecast error variance demcoposition for three different forecast horizons evaluated at the posterior mode. From top to bottom: consumption, nominal interest rate, annual inflation, employment, real wage rate, real marginal cost, hours worked, vacancies. From left to right: inflation target shock, demand (preference) shock, technology shock, cost-push shock, vacancy posting cost shock, disutility of work shock. All entries are in $\%$. 
Figure 3: Error Decomposition
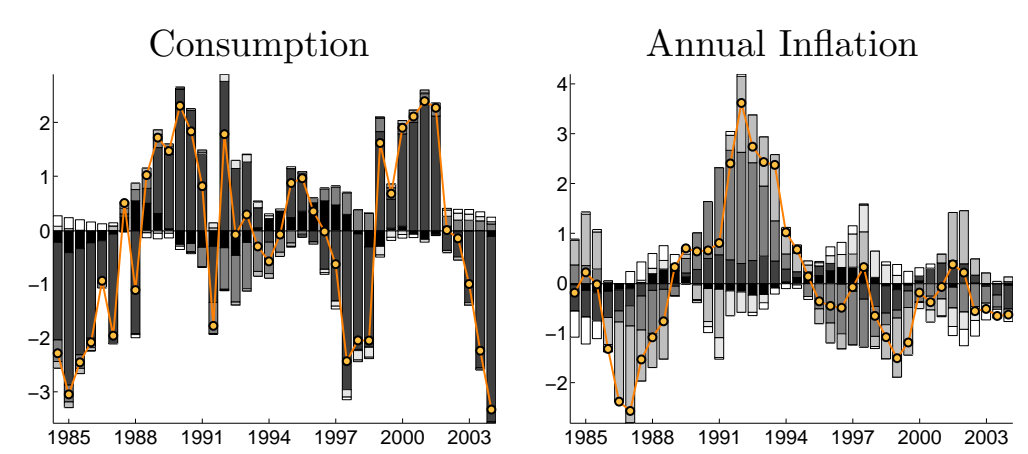

Nominal Rate

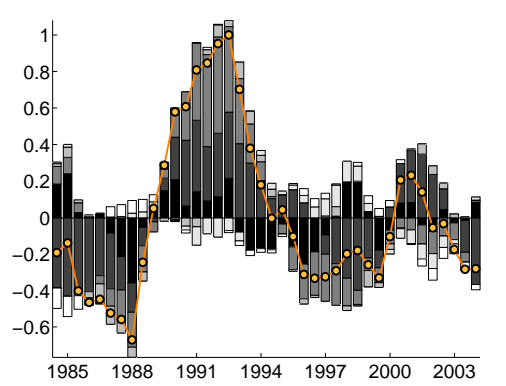

Legend

Employment
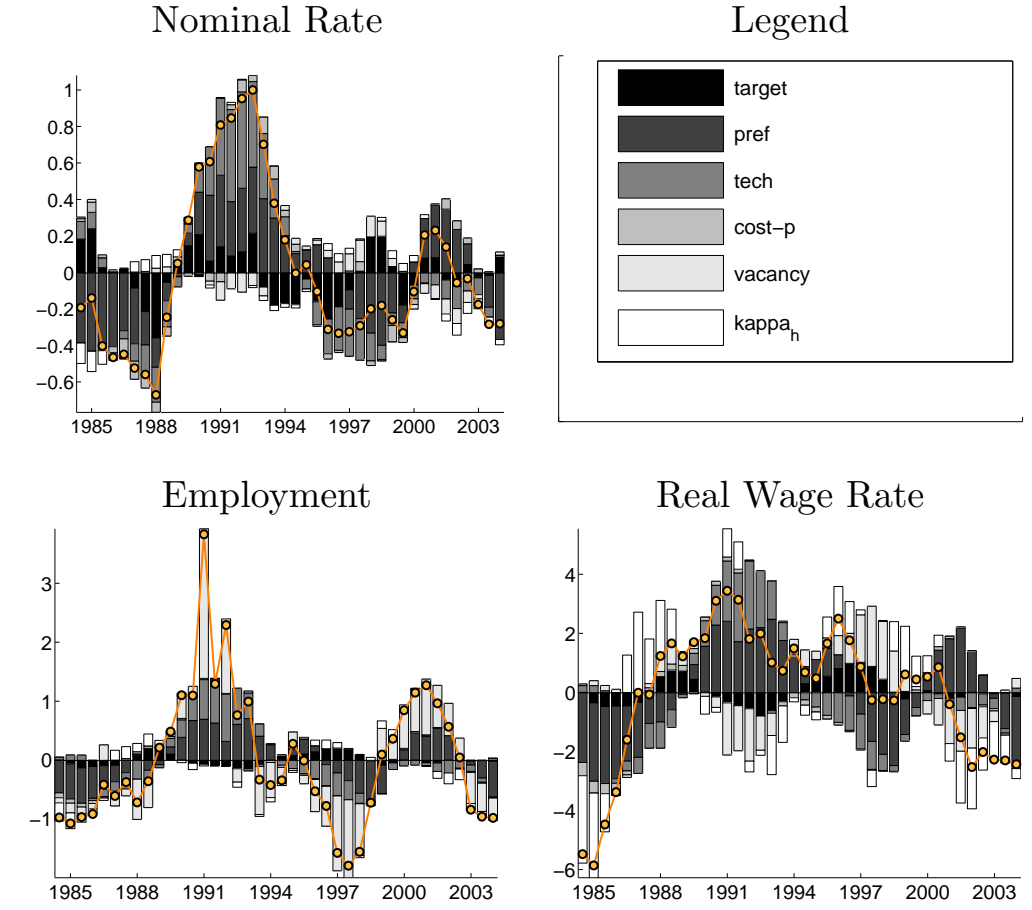

Real Wage Rate

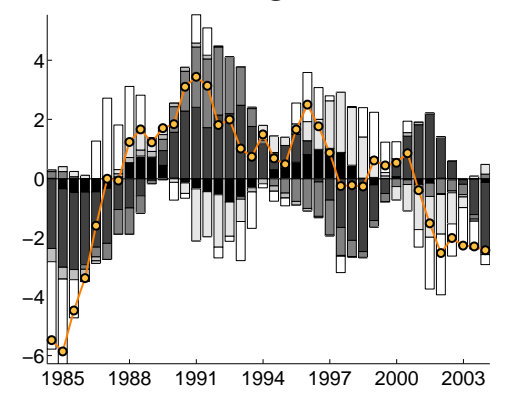

Notes: Business cycle error decomposition. After running the Kalmansmoother the actual time series (orange line marked by circles) is decomposed into its contributing forces, i.e. into the contributions by each shock process. Only every second observation is reported in order to keep the graphs readable. 
target shock and the cost push shock are irrevelant for labor market fluctuations. ${ }^{27}$ In general, unsystematic monetary policy (i.e. the monetary policy shock) is not a suspect for being an important determinant of fluctuations in the labor market.

The Keynesian nature of our model becomes most apparent when examining the effect of a positive technology shock (see Figure 4). Hours worked fall as less labor input is required to produce the demand determined output. ${ }^{28}$ This reinforces the increase in the marginal product of labor caused by the technology shock. In addition, the marginal disutility of work falls, reducing the real wage rate. Marginal costs fall driven by both the falling wage rate and the increased marginal product of labor. Inflation falls accordingly. The associated interest rate reductions via the central bank reaction function increase consumption gradually. Period profits are tightly linked to the dynamics in hours and wages; cp. equation (33) in Appendix A. Therefore, lower wages and hours come along with lower profits and hence reduced vacancy posting intensity. ${ }^{29}$ This causes a rise in unemployment. The autocorrelated technology shock imposes a significant degree of persistence on the real and nominal variables.

In terms of the variance decomposition (cp. Table 6 and Figure 3 again), the technology shock is a key determinant of marginal cost (determining 37\% of its fluctuations in the short and $50 \%$ in the long run). Hence productivity fluctuations in our model are very important for inflation, determining $12 \%$ of its variability in the short-run and more than half in the long-run. In the long run, technology also plays an important role for real wage and consumption fluctuations. The figures are $20 \%$ and $8 \%$, respectively.

27 The inflation target shock is rather important for interest rate fluctuations determining $50 \%$ of its fluctuations in the short run and $14 \%$ in the long run. The cost push shock mainly drives the inflation rate and hardly spills over to other variables (apart from interest rates). It explains $88 \%$ of inflation variations in the short-run and still $38 \%$ in the long-run; qualitatively similar to the results in Smets and Wouters (2003).

28 The response of hours worked to technology shocks recently has caused an intense discussion in the profession. The fall of hours worked in response to a technology shock is in line with evidence reported in Gali (1999) and Francis and Ramey (2002), for instance.

29 The response of vacancies is not hump-shaped. To achieve this Braun (2005) introduces vacancy adjustment costs and Yashiv (2006) uses convex hiring costs. Fujita and Ramey (2005) modify the model in a more substantial way. They add a job creation cost (a fixed cost payable once which is not the same for each job) as opposed to a vacancy posting cost (a cost payable each period the vacancy is open) to the model. Once a job is created, posting a vacancy is costless. This makes vacancies a state variable. Since shocks are persistent there will be new profitable job opportunities in the next period. Thus vacancies continue to build up, leading to a more sluggish (and hump-shaped) adjustment of vacancies. Yet the behavior of vacancies is not the main focus of our paper, we therefore stick to the standard model. 
Figure 4: Impulse Responses to 1\% Technology Shock.

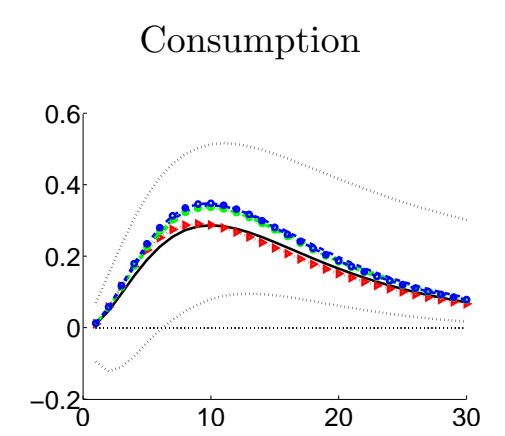

Unemployment

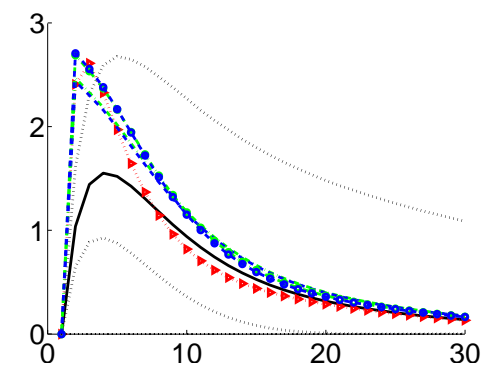

Hours per Worker

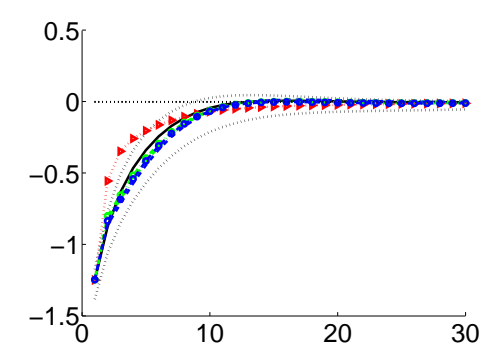

Quarterly Inflation

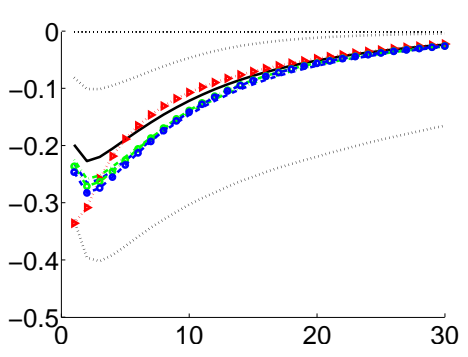

Vacancies

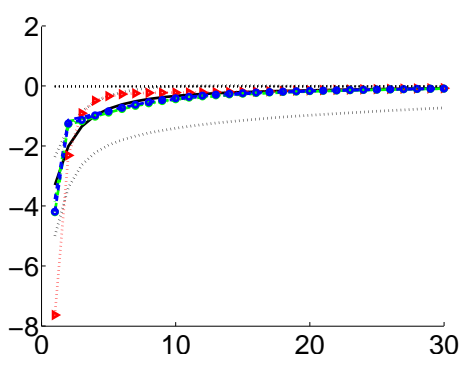

Marginal Cost

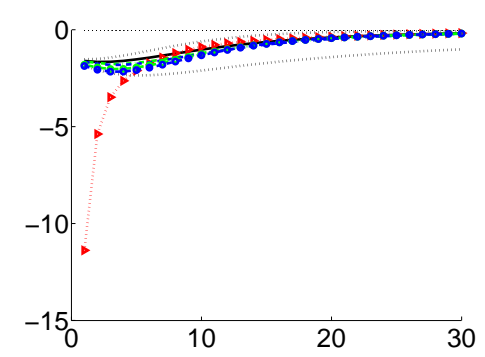

Nominal Rate

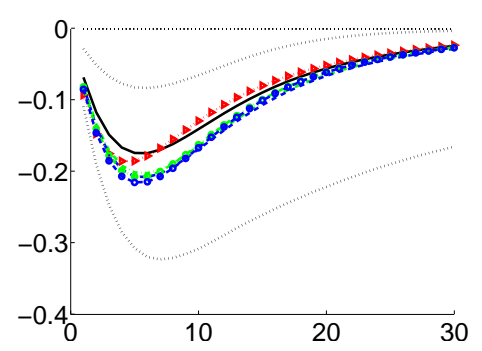

Period Profits

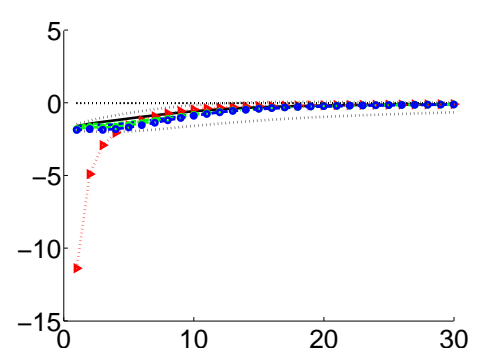

Real Wage Rate

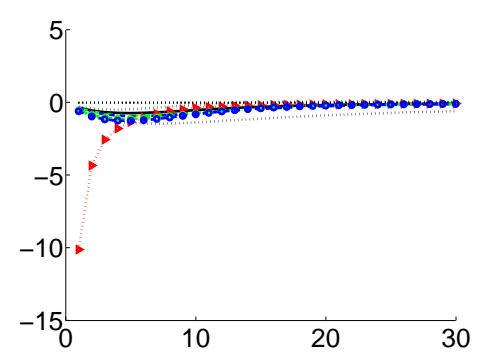

Notes: The graphs show percentage responses (1 in the plots corresponds to 1\%) of endogenous variables to a one percent technology shock. The black solid line marks the estimated model (at the posterior mode). Black dotted lines mark 95\% confidence intervals (using 100.000 draws from the posterior distribution). The red line marked by triangles shows the case of no wage rigidity. The remaining blue dashed lines and the green dashed-dotted lines correspond to the counterfactual flexible labor market experiments described in more detail in Appendix E. Nb: an increase of unemployment of 1 in the plot means that the unemployment rate increases by $1 \%$, say from 0.15 to 0.1515 ; not by one percentage point! 
The demand preference shock stimulates current consumption (see Figure 5). The increased demand requires additional labor input which initially is fully provided by an extension of hours worked. Higher expected profits translate into more vacancy posting and hence into an increase in employment. The demand shock induces a positive correlation between all main variables as it is found in the data (compare Table 9 in Appendix B for the cross correlations in the data).

Looking at the variance decomposition, it appears that the demand shock drives all consumption movement in the short run and still $89 \%$ in the long run. It explains roughly $30 \%$ of real wage movements and marginal cost. Yet as we have argued above there are other shocks, in particular technology shocks, which have more influence on marginal cost and thus on inflation. The demand shock is thus not a strong driving force of inflation: not more than $5 \%$ of the forecast error variance of inflation are due to the demand shock. ${ }^{30}$

In brief, our results show that the labor market helps to understand the transmission of monetary policy on inflation. Our counterfactual exercises display that the more rigid the labor market is, and in particular the more rigid the real wage is, the more persistent is the response of inflation to an inflation target shock. Moreover, we can show that labor market shocks transmit only marginally into the dynamics of non-labor market variables in the model. A thorough welfareanalysis notwithstanding, this may raise some doubt whether shocks originating in the labor market are important information for monetary policy.

${ }^{30}$ For the sake of brevity, we do not report impulse responses to price-markup and disutility of work shocks here. These will be made available upon request. 
Figure 5: Impulse Responses to 1\% Preference Shock.

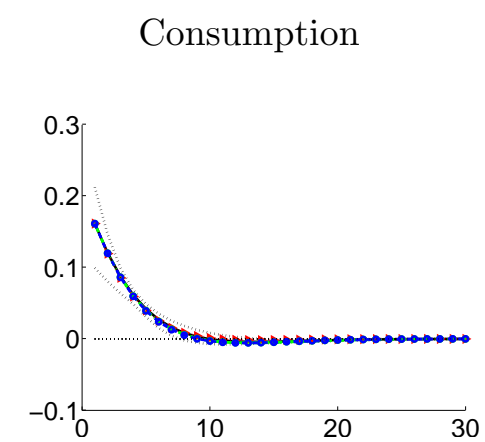

Quarterly Inflation

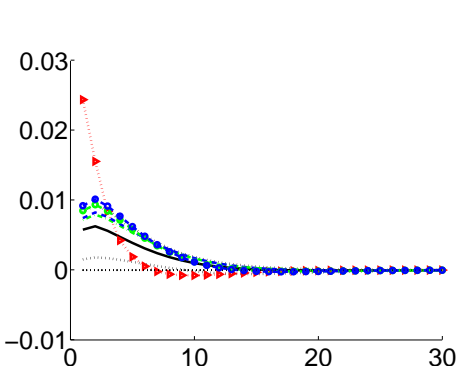

Vacancies

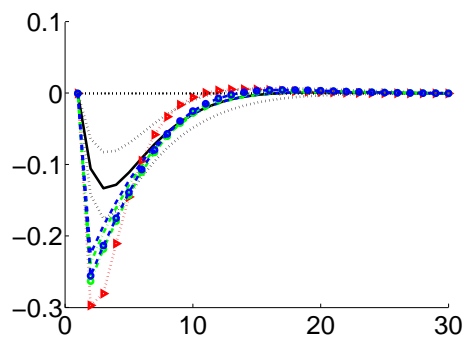

Hours per Worker
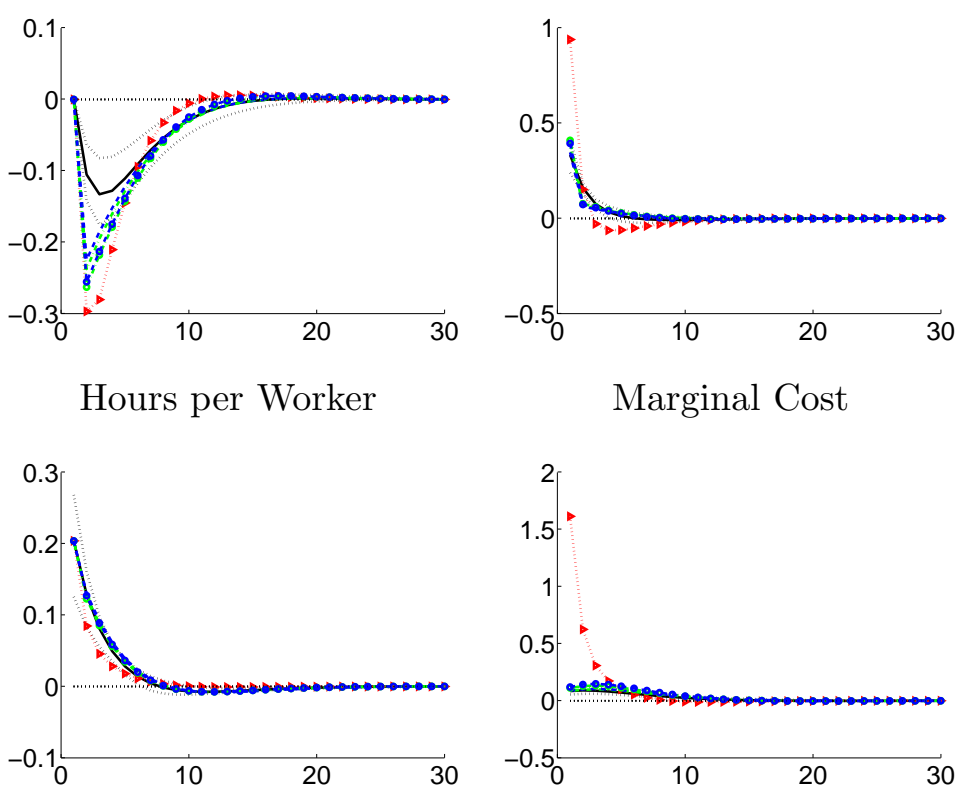

Marginal Cost
Nominal Rate

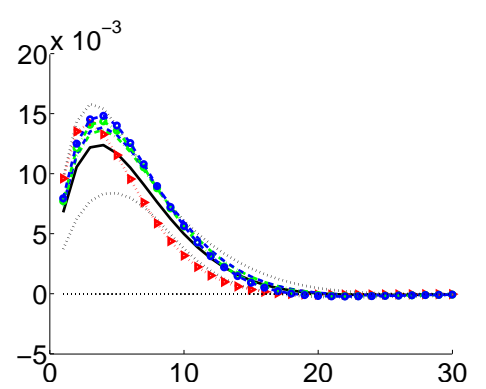

Period Profits

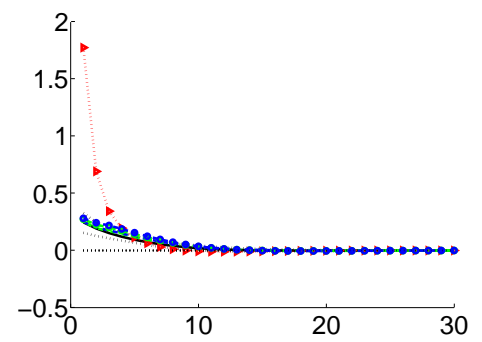

Real Wage Rate

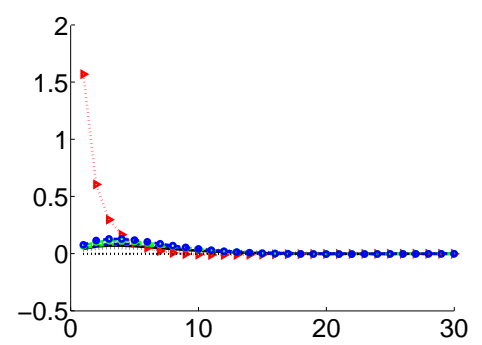

Notes: The graphs show percentage responses ( 1 in the plots corresponds to $1 \%$ ) of endogenous variables to a one percent preference shock. The black solid line marks the estimated model (at the posterior mode). Black dotted lines mark 95\% confidence intervals (using 100.000 draws from the posterior distribution). The red line marked by triangles shows the case of no wage rigidity. The remaining blue dashed lines and the green dashed-dotted lines correspond to the counterfactual flexible labor market experiments described in more detail in Appendix E. Nb: an increase of unemployment of 1 in the plot means that the unemployment rate increases by $1 \%$, say from 0.15 to 0.1515 ; not by one percentage point! 


\section{Conclusions}

In this paper we estimate a small-scale DSGE model with search and matching frictions by Bayesian full-information techniques. We focus on a quantitative assessment of the role of labor markets in a stable monetary policy regime. Towards that aim we use German data in order to avoid possible problems with regard to the heterogeneity of labor market and monetary policy regimes across the euro area in pre-EMU years.

To account for wage and inflation persistence we model quadratic wage adjustment costs in the search and matching framework. Using a set of structural shocks including a labor market specific shock we are able to present evidence on the relative importance of specific disturbances. Furthermore we assess the role of labor market rigidities for monetary policy by counterfactual policy simulations.

Our results can be summarized as follows. First, we find that the structure of the labor market matters substantially for the overall behavior of the economy and the transmission of monetary policy on inflation in particular. The specific settings of the labor market, as for example the degree of wage inertia or the efficiency of the matching process, are found to have a notable impact. The influence of the labor market is stronger for inflation than for aggregate demand. Specifically, we find that the degree of wage rigidity is positively correlated with inflation persistence. In addition, if the frictions associated with finding a new job are sizeable, our results show that the effects of shocks on inflation last longer. Furthermore we find that a higher degree of wage rigidity amplifies real adjustment in the labor market and leads to more fluctuations in employment.

Second, the realization of labor market shocks has an impact on the labor market itself but a limited influence on the other blocks of the model. Therefore labor market shocks do not contribute much to the cyclical dynamics of non-labor market variables - particularly inflation. This suggests that the model does not feature much transmission from labor markets to the rest of the economy. In our model, consumers perfectly insure each other against shortfalls of consumption due to unemployment. Easing this assumption would likely introduce further transmission. In addition, a further natural candidate for a change in the model structure is more closely tying price setting decisions to decisions in the labor market like hiring and wage setting. 
In total, to the extent the European Central Bank's task is to keep inflation low (and stable), policy makers need to have a good understanding of the structure of the labor-market. The realization of labor market specific shocks, however, to a first (coarse) approximation does not appear to contain much information for the conduct of monetary policy if its aim is to achieve stable inflation and to stabilize output around its long-run trend.

Pointing to future research, this latter conclusion comes with the proviso that we leave aside one important welfare-theoretic consideration: while labor market shocks may not alter actual output, they can have a bearing on natural (flex-price) or efficient output, see e.g. Blanchard and Gali (2005). This would in turn matter for the conduct of truely optimal monetary policy. We are currently exploring this point in ongoing research.

\section{References}

Abel, A. (1990): "Asset Prices under Habit Formation and Catching Up with the Joneses," American Economic Review, 80(2), 38-42.

Altig, D., L. J. Christiano, M. Eichenbaum, and J. Linde (2005): "Firm-Specific Capital, Nominal Rigidities and the Business Cycle," NBER Working Paper No. 11034.

Bachmann, R. (2005): "Labour Market Dynamics in Germany: Hirings, Separations, and Job-toJob Transitions over the Business Cycle," Humboldt University: SFB Discussion Paper 2005-45.

Blanchard, O., and J. Gali (2005): "Real Wage Rigidities and the New Keynesian Model," MIT Department of Economics Working Paper No. 05-28.

Boldrin, M., L. Christiano, and J. Fisher (2001): "Habit Persistence, Asset Returns and the Business Cycle," American Economic Review, 91(1), 149-166.

Braun, H. (2005): "(Un)employment Dynamics: The Case of Monetary Policy Shocks," mimeo; Northwestern University.

Burda, M., And C. Wyplosz (1994): "Gross Worker and Job Flows in Europe," European Economic Review, 38(6), 1287-1315.

Calvo, G. (1983): "Staggered Prices in a Utility Maximizing Framework," Journal of Monetary Economics, 12(3), 383-398.

Christiano, L. J., M. Eichenbaum, and C. Evans (2005): "Nominal Rigidities and the Dynamic Effects of a Shock to Monetary Policy," Journal of Political Economy, 113(1), 1-45. 
Christoffel, K., and T. Linzert (2005): "The Role of Real Wage Rigidity and Labor Market Frictions for Unemployment and Inflation Dynamics," European Central Bank Working Paper No. 556 .

Clarida, R., J. Gali, and M. Gertler (1998): "Monetary Policy Rules in Practice. Some International Evidence," European Economic Review, 42(6), 1033-1067.

(2000): "Monetary Policy Rules and Macroeconomic Stability: Evidence and Some Theory," Quarterly Journal of Economics, 115, 147-180.

del Negro, M., F. Schorfheide, F. Smets, and R. Wouters (2004): "On the Fit and Forecasting Performance of New Keynesian Models," Federal Reserve Bank of Atlanta Working Paper 2004-3\%.

Eichenbaum, M., and J. Fisher (2003): "Evaluating the Calvo Model of Sticky Prices," Federal Reserve Bank of Chicago, Working Paper 2003-23.

Francis, N., and V. A. Ramey (2002): "Is the Technology-Driven Real Business Cycle Hypothesis Dead? Shocks and Aggregate Fluctuations Revisited," NBER Working Paper No. 8726.

Funrer, J. (2000): "Habit Formation in Consumption and Its Implications for Monetary-Policy Models," American Economic Review, 90(3), 367-390.

Fujita, S., And G. Ramey (2005): "The Dynamic Beveridge Curve," Federal Reserve Bank of Philadelphia Working Paper No. 05-22.

Gali, J. (1999): "Technology, Employment and the Business Cycle: Do Technology Shocks Explain Aggregate Fluctuations?," American Economic Review, 89(1), 249-271.

Gali, J., M. Gertler, And D. LóPez-SAlido (2001): "European Inflation Dynamics," European Economic Review, 45(7), 1237-1270.

Gertler, M., And A. Trigari (2005): "Unemployment Fluctuations with Staggered Nash Wage Bargaining," mimeo; New York University.

Hall, R. (2005): "Employment Fluctuations with Equilibrium Wage Stickiness," American Economic Review, 95(1), 50-65.

Hoffmann, J., and J.-R. Kurz-Kim (2004): "Consumer Price Adjustment Under the Microscope: Germany in a Period of Low Inflation," Unpublished Manuscript; proceeding of the "Inflation Persistence Network".

Kuester, K. (2006): "Real Price and Wage Rigidities in a Model with Matching Frictions," mimeo, Goethe University Frankfurt.

Lubik, T., And F. Schorfheide (2005): "A Bayesian Look at New Open Economy Models," NBER Macroeconomics Annual, 2005, forthcoming.

Mortensen, D., and C. Pissarides (1994): "Job Creation and Job Destruction in the Theory of Unemployment," Review of Economic Studies, 61(3), 397-415. 
Schorfheide, F. (2000): "Loss Function-based Evaluation of DSGE Models," Journal of Applied Econometrics, 15(6), 645-670.

Shimer, R. (2004): "The Consequences of Rigid Wages in Search Models," Journal of the European Economic Association, 2(2).

(2005): "The Cyclical Behavior of Equilibrium Unemployment, Vacancies, and Wages: Evidence and Theory," American Economic Review, 95(1), 25-49.

Smets, F., And R. Wouters (2003): "An Estimated Stochastic Dynamic General Equilibrium Model of the Euro Area," Journal of the European Economic Association, 1(5), 1123-75.

TAYlor, J. B. (1993): "Discretion Versus Policy Rules in Practice," Carnegie-Rochester Conference Series on Public Policy, 39(December), 195-214.

Trigari, A. (2004): "Equilibrium Unemployment, Job Flows and Inflation Dynamics," ECB Working Paper No. 304.

(2006): "The Role of Search Frictions and Bargaining for Inflation Dynamics," IGIER Working Paper No. 304.

Woodford, M. (2003): Interest and Prices: Foundations of a Theory of Monetary Policy. Princeton University Press, Princeton.

YAshiv, E. (2006): "Evaluating the Performance of the Search and Matching Model," IZA discussion paper No. 1931. 


\section{A Linearized Model}

\section{A.1 Equations independent of the right-to-manage specification}

$$
\begin{gathered}
\widehat{\lambda}_{t}=\widehat{r}_{t}^{\text {real }}+E_{t} \widehat{\lambda}_{t+1} . \\
\widehat{\lambda}_{t}=\epsilon_{t}^{\text {pref }}-\frac{\sigma}{1-h_{c}}\left\{\widehat{c}_{t}-h_{c} \widehat{c}_{t-1}\right\} .
\end{gathered}
$$

This implies the Euler equation

$$
\begin{aligned}
& \widehat{c}_{t}=\frac{h_{c}}{1+h_{c}} \widehat{c}_{t-1}+\frac{1}{1+h_{c}} E_{t} \widehat{c}_{t+1}-\frac{1-h_{c}}{\sigma\left(1+h_{c}\right)} \widehat{r}_{t}^{\text {real }}+\frac{1-h_{c}}{\sigma\left(1+h_{c}\right)}\left(\widehat{\epsilon}_{t}^{\text {pref }}-E_{t} \widehat{\epsilon}_{t+1}^{\text {pref }}\right) . \\
& \widehat{r}_{t}^{r e a l}=\widehat{R}_{t}-E_{t} \widehat{\pi}_{t+1} \text {. } \\
& \widehat{y}_{t}=\widehat{n}_{t}+\widehat{z}_{t}+\alpha \widehat{h}_{t} \text {. } \\
& \widehat{m}_{t}=\bar{\sigma}_{2} \widehat{u}_{t}+\left(1-\bar{\sigma}_{2}\right) \widehat{v}_{t} \text {. } \\
& \widehat{s}_{t}=\widehat{m}_{t}-\widehat{u}_{t} . \\
& \widehat{q}_{t}=\widehat{m}_{t}-\widehat{v}_{t} . \\
& \widehat{\theta}_{t}=\widehat{s}_{t}-\widehat{q}_{t}=\widehat{v}_{t}-\widehat{u}_{t} . \\
& \widehat{n}_{t}=(1-\rho) \widehat{n}_{t-1}+\rho \widehat{m}_{t-1} \text {. } \\
& \widehat{u}_{t}=-(1-\rho) \frac{\bar{n}}{\bar{u}} \widehat{n}_{t} \text {. } \\
& \widehat{q}_{t}=\widehat{\kappa}_{t}-(1-\beta(1-\rho)) E_{t} \widehat{\lambda}_{t+1}+\frac{\rho}{1-\rho} E_{t} \widehat{\rho}_{t+1}-(1-\beta(1-\rho)) E_{t} \widehat{\psi}_{t+1}+\beta(1-\rho) E_{t}\left\{\widehat{q}_{t+1}-\widehat{\kappa}_{t+1}\right\} . \\
& \widehat{\psi}_{t}=\frac{1}{\bar{\psi}}\left\{\bar{x} \bar{z}^{\alpha}\left\{\widehat{x}_{t}+\widehat{z}_{t}+\alpha \widehat{h}_{t}\right\}-\bar{w} \bar{h}\left\{\widehat{w}_{t}+\widehat{h}_{t}\right\}\right\} . \\
& \widehat{m p l}_{t}=\widehat{z}_{t}+(\alpha-1) \widehat{h}_{t} . \\
& \widehat{m r s} s_{t}=\widehat{\kappa}_{h t}+\phi \widehat{h}_{t}-\widehat{\lambda}_{t} \text {. } \\
& \widehat{R}_{t}=\rho \widehat{R}_{t-1}+(1-\rho) \gamma_{\pi}\left(\widehat{\pi}_{t+1 \mid t}-\widehat{\bar{\pi}}_{t}\right)+(1-\rho) \gamma_{y} \widehat{y}_{t} . \\
& \widehat{\pi}_{t}=\frac{\beta}{1+\beta \gamma} E_{t} \widehat{\pi}_{t+1}+\frac{\gamma}{1+\beta \gamma} \widehat{\pi}_{t-1}+\frac{(1-\varphi)(1-\varphi \beta)}{\varphi(1+\beta \gamma)}\left(\widehat{x}_{t}+\widehat{e}_{t}\right) . \\
& \widehat{e}_{t}=\frac{1}{1-\bar{\epsilon}} \widehat{\epsilon}_{t}^{c p} .
\end{aligned}
$$




\section{A.2 First-order conditions of bargaining with right-to-manage}

\section{A.2.1 Hours}

$$
\widehat{x}_{t}+\widehat{m p l}_{t}=\widehat{w}_{t} .
$$

implying

$$
\widehat{x}_{t}+\widehat{z}_{t}+(\alpha-1) \widehat{h}_{t}=\widehat{w}_{t} .
$$

Note also that for right-to-manage bargaining ${ }^{31}$

$$
\widehat{\psi}_{t}=\widehat{w}_{t}+\widehat{h}_{t} .
$$

\section{A.2.2 Real wage rate}

$$
\begin{aligned}
& \widehat{w}_{t}=\xi_{1} \widehat{\chi}_{t}+\gamma_{1} \widehat{m r s} s_{t}+\gamma_{2}\left(\widehat{\kappa}_{t}+\widehat{\theta}_{t}-\widehat{\lambda}_{t}-\widehat{h}_{t}\right)-\gamma_{3} \widehat{h}_{t}-\xi_{2} E_{t} \widehat{\chi}_{t+1} \text {. } \\
& \xi_{1}=\frac{1}{1-\frac{\bar{\chi}}{\alpha}}\left\{\bar{\chi}\left\{\frac{1}{\alpha}+\frac{\bar{\kappa} \bar{\theta}}{\overline{\lambda h} \bar{w}}-\frac{\overline{m r s}}{\bar{w}(1+\phi)}-\frac{\bar{b}}{\bar{h} \bar{w}}\right\}+\frac{\bar{\chi}}{1-\bar{\chi}}\left\{\frac{\bar{\kappa}}{\bar{\lambda} \bar{q} \bar{h} \bar{w}}(1-\bar{s})\right\}\right\} . \\
& \xi_{2}=\frac{1}{1-\frac{\bar{\chi}}{\alpha}}\left\{(1-\bar{s}) \frac{\bar{\kappa}}{\bar{\lambda} \bar{q} \bar{h} \bar{w}} \frac{\bar{\chi}}{1-\bar{\chi}}\right\} \text {. } \\
& \gamma_{1}=\frac{1}{1-\frac{\bar{\chi}}{\alpha}}\left\{\frac{\overline{m r s}}{\bar{w}(1+\phi)}(1-\bar{\chi})\right\} \text {. } \\
& \gamma_{2}=\frac{1}{1-\frac{\bar{\chi}}{\alpha}}\left\{\bar{\chi} \frac{\bar{\kappa} \bar{\theta}}{\overline{\lambda h} \bar{w}}\right\} \text {. } \\
& \gamma_{3}=\frac{1}{1-\frac{\bar{\chi}}{\alpha}}\left\{(1-\bar{\chi}) \frac{\bar{b}}{\bar{h} \bar{w}}\right\} \text {. } \\
& \widehat{\chi}_{t}=(1-\bar{\chi})\left\{\widehat{\delta}_{t}^{w, w}-\widehat{\delta}_{t}^{f, w}\right\} \text {. } \\
& \widehat{\delta}_{t}^{w, w}=\widehat{h}_{t}-\frac{\frac{\overline{m r s}}{\bar{w}}}{\alpha-\frac{\overline{m r s}}{\bar{w}}}\left(\widehat{m r s} t-\widehat{w}_{t}\right) \text {. } \\
& \widehat{\delta}_{t}^{f, w}=\widehat{h}_{t}+\frac{\bar{w}}{\bar{h}} \phi_{L}\left[\left(\widehat{w}_{t}-\widehat{w}_{t-1}\right)-\beta(1-\rho)\left(\widehat{w}_{t+1 \mid t}-\widehat{w}_{t}\right)\right] .
\end{aligned}
$$

We define $\phi_{L}^{\text {new }}:=\frac{\bar{w}}{\bar{h}} \phi_{L} / 1000$.

${ }^{31}$ Using the definition of profits and the FOC for hours,

$$
\psi_{t}+\text { adj. costs }=x_{t} z_{t} h_{t}^{\alpha}-w_{t} h_{t}=x_{t} m p l_{t} \frac{h_{t}}{\alpha}-w_{t} h_{t}=w_{t} h_{t}\left[\frac{1-\alpha}{\alpha}\right] .
$$

Since adjustment costs have no first-order effect on profits, in equilibrium profits are tightly linked to the total wage bill. 


\section{B Data}

Table 7: Data Description and Sources

Price level

Nominal interest rate

Vacancies

Consumption

Labor force

Employment

Wages

Hours
Consumer price index, CPI all items, base year 2000, own seasonal adjustment. Source: OECD.

3-month money market interest rate, interbank market. Frankfurt, monthly average, $\%$ p.a. Source: OECD.

Unfilled job vacancies, seasonally adjusted, Quantum (non-additive or stock figures), in 1000. persons Source: OECD.

Private final consumption expenditure, GDP by expenditure, quarterly levels, 1995 prices, seasonally adjusted.

Source: OECD.

Total labor force, in 1000 persons, own seasonal adjustment. Source: OECD.

Civilian employment (survey), seasonally adjusted, all persons, all ages, in 1000 persons.

Source: OECD.

Hourly earnings: manufacturing, index publication base, base year 2000, seasonally adjusted.

Source: OECD.

Hours of work total industry, excluding construction, seasonally adjusted.

Source: Eurostat. 
Figure 6: Plots of the Detrended and Demeaned Series

yert

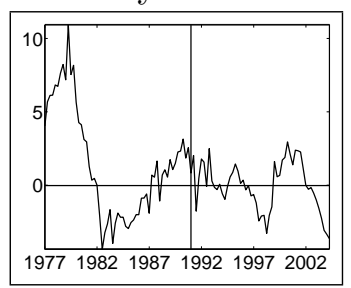

hourst

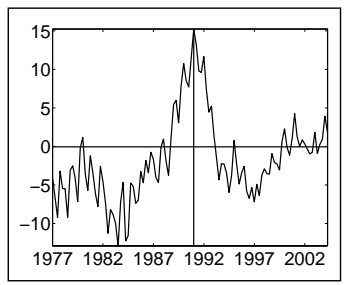

emplt

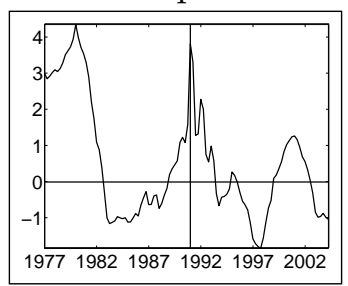

pict_ann

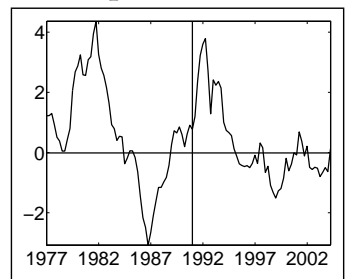

vact

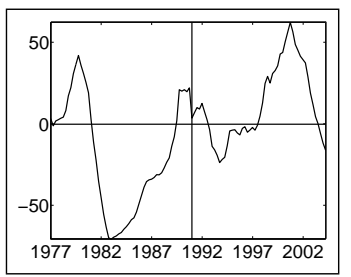

rtnt

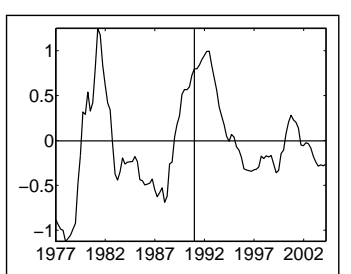

wtrt

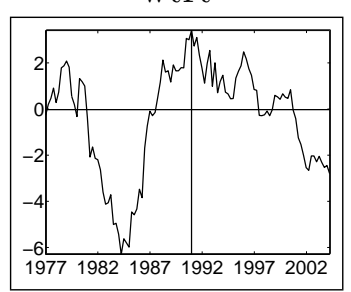

rtntreal

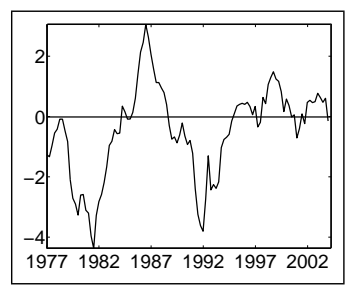

Notes: Data used as log-deviations from a respective trend (see below). The inflation series marks annual (year on year) inflation as log-deviations from a respective trend. The data span 1977:1 to 2004:2. All series are multiplied by 100 in order to give percentage deviations from steady state. The trends and constants have been computed using data from 1984:3 to 2004:2. Log consumption was regressed on a constant, a reunification dummy and a linear trend. Log employment rates were demeaned and detrended. Vacancies were computed as vact $:=($ Vact - mean $(V a c t)) /$ mean $($ Vact $)$ and hence not detrended. Log real wage rates were regressed on a constant and a linear trend. Log hours worked were demeaned and detrended. Inflation rates were demeaned and linear detrended. The interest rate was demeaned and linear detrended. 
Table 8: Standard Deviation and Persistence

\begin{tabular}{lccrrrr}
\hline Names & std & sum1 & sum2 & sum3 & sum4 & sum5 \\
\hline \hline$\widehat{r}_{t}$ & 0.4368 & 0.9734 & 0.9606 & 0.9551 & 0.9398 & 0.9376 \\
$\widehat{y}_{t}$ & 1.7292 & 0.7999 & 0.8605 & 0.8328 & 0.8329 & 0.7819 \\
$\widehat{v}_{t}$ & 30.0150 & 0.9561 & 0.9598 & 0.9565 & 0.9510 & 0.9520 \\
$\widehat{n}_{t}$ & 1.0887 & 0.9062 & 0.8797 & 0.9347 & 0.9035 & 0.8753 \\
$\widehat{w}_{t}$ & 2.2260 & 0.9296 & 0.9200 & 0.9065 & 0.9249 & 0.9205 \\
$\widehat{h}_{t}$ & 5.3275 & 0.8593 & 0.8867 & 0.9139 & 0.9139 & 0.8944 \\
$\widehat{\pi}_{t}^{a n n}$ & 1.3228 & 0.9335 & 0.9176 & 0.9114 & 0.8963 & 0.9246 \\
\hline
\end{tabular}

Notes: "sum1" is the first-order autoregression coefficient (OLS), "sum2" is the sum of the first two autoregression coefficients (OLS) and so forth. "Std" is the standard deviation of the time series. The data span 1984:3 to 2004:2.

Table 9: Cross-correlations

\begin{tabular}{lccccccc}
\hline Names & $\widehat{r}_{t}$ & $\widehat{y}_{t}$ & $\widehat{v}_{t}$ & $\widehat{n}_{t}$ & $\widehat{w}_{t}$ & $\widehat{h}_{t}$ & $\widehat{\pi}_{t}^{\text {ann }}$ \\
\hline$\widehat{r}_{t}$ & 1.0000 & 0.4755 & 0.3578 & 0.7658 & 0.4866 & 0.7403 & 0.8506 \\
$\widehat{y}_{t}$ &. & 1.0000 & 0.5185 & 0.7146 & 0.5948 & 0.4937 & 0.2374 \\
$\widehat{v}_{t}$ &. &. & 1.0000 & 0.4891 & 0.3395 & 0.3863 & 0.1383 \\
$\widehat{n}_{t}$ &. &. &. & 1.0000 & 0.4772 & 0.7972 & 0.4833 \\
$\widehat{w}_{t}$ &. &. &. &. & 1.0000 & 0.4748 & 0.3676 \\
$\widehat{h}_{t}$ &. &. &. &. &. & 1.0000 & 0.4772 \\
$\widehat{\pi}_{t}^{a n n}$ &. &. &. &. &. &. & 1.0000 \\
\hline
\end{tabular}

Notes: Cross-correlations of the data computed from 1984:3 to 2004:2. 


\section{Further Estimation Statistics for the Parameters}

Table 10: Summary Statistics for Estimated Parameters

\begin{tabular}{|c|c|c|c|c|c|c|c|c|}
\hline \multirow[t]{2}{*}{ Parameter } & \multicolumn{3}{|l|}{ prior } & \multicolumn{5}{|c|}{ posterior } \\
\hline & mean & std & distr. & mean & median & mode & $95 \% \mathrm{c}$ & interval \\
\hline \multicolumn{9}{|c|}{ Parameters of Structural Model } \\
\hline$\rho_{m}$ & 0.750 & 0.0500 & norm & 0.80 & 0.80 & 0.78 & 0.73 & 0.86 \\
\hline$\gamma_{\pi}$ & 1.500 & 0.3000 & norm & 1.46 & 1.45 & 1.40 & 1.01 & 1.92 \\
\hline$\gamma_{y}$ & 0.125 & 0.3000 & norm & 0.21 & 0.21 & 0.19 & 0.10 & 0.34 \\
\hline$h_{c}$ & 0.850 & 0.0500 & norm & 0.83 & 0.84 & 0.83 & 0.77 & 0.89 \\
\hline$\varphi$ & 0.900 & 0.0500 & norm & 0.93 & 0.93 & 0.92 & 0.90 & 0.95 \\
\hline$\gamma_{p}$ & 0.300 & 0.1000 & norm & 0.27 & 0.27 & 0.26 & 0.14 & 0.41 \\
\hline$\sigma_{2}$ & 0.400 & 0.0500 & norm & 0.33 & 0.33 & 0.31 & 0.23 & 0.43 \\
\hline$\phi_{L}^{n e w}$ & 0.250 & 0.1000 & norm & 0.37 & 0.37 & 0.36 & 0.27 & 0.47 \\
\hline \multicolumn{9}{|c|}{ Serial Correlation of Shocks } \\
\hline$\rho_{\overline{\bar{\pi}}}$ & 0.300 & 0.2000 & norm & 0.35 & 0.36 & 0.36 & 0.17 & 0.55 \\
\hline$\rho_{\kappa}$ & 0.700 & 0.1000 & norm & 0.60 & 0.61 & 0.60 & 0.49 & 0.72 \\
\hline$\rho_{z}$ & 0.900 & 0.0250 & norm & 0.93 & 0.93 & 0.93 & 0.88 & 0.98 \\
\hline$\rho_{\kappa_{h}}$ & 0.300 & 0.1000 & norm & 0.21 & 0.21 & 0.20 & 0.05 & 0.36 \\
\hline \multicolumn{9}{|c|}{ "Standard Deviation of Innovations } \\
\hline$\mu^{\bar{\pi}}$ & 0.007 & Inf & invg & 0.003 & 0.003 & 0.003 & 0.002 & 0.004 \\
\hline$\mu^{p r e f}$ & 0.100 & $\operatorname{Inf}$ & invg & 0.074 & 0.072 & 0.068 & 0.048 & 0.105 \\
\hline$\mu^{z}$ & 0.006 & Inf & invg & 0.004 & 0.005 & 0.004 & 0.002 & 0.007 \\
\hline$\mu^{\text {cost-push }}$ & 0.001 & $\operatorname{Inf}$ & invg & 0.003 & 0.003 & 0.003 & 0.002 & 0.004 \\
\hline$\mu^{\kappa}$ & 0.010 & $\operatorname{Inf}$ & invg & 0.028 & 0.028 & 0.025 & 0.016 & 0.043 \\
\hline$\mu^{\kappa_{h}}$ & 0.200 & 0.1000 & norm & 0.443 & 0.443 & 0.435 & 0.336 & 0.553 \\
\hline
\end{tabular}

Notes: Parameter estimates using 100.000 draws (after burn in) in the Metropolis-Hastings algorithm. Nota bene: The underlying calibration is such that $\bar{q}=0.7391, \bar{s}=0.4928, \bar{w} \bar{h} / \bar{y}=\alpha=0.72, \bar{\kappa} /(\bar{\lambda} \bar{y})=1.4771$, $b /(\bar{w} \bar{h})=0.5, \bar{u}=0.15$ and $\bar{v}=0.1$. 


\section{Cross-correlation}

Figure 7 compares model cross-correlations to the cross-correlations measured in the data. those of the data. The black solid line marks model cross-correlations (evaluated at the posterior mode, again). The black dash-dotted lines mark $95 \%$ coverage intervals. The figure also shows VAR(2) cross-correlations (read and dotted) as a data summary. These are framed by dotted blue $95 \%$ bootstrapped confidence intervals from the VAR. Overall, the model's cross-correlations match the data's well - especially the autocorrelation properties. Still, a few properties are not matched by our model to which we turn next: First, the correlation between consumption and interest rates is not yet sufficiently positive (row 1 , column 2 ; row 2 , column 1 ). Second, in the data consumption is a predictor for future inflation. Our model does not match this fact (row 1, column 3; row 3, column 1). Presumably, these correlations could be brought closer to the data by a more judicious choice of the monetary policy rule. In our model, the monetary authority is the only sector which is not optimizing. In principle that leaves many degrees of freedom for modelling the interest rate reaction function. However, more sophisticated (performance oriented, say) policy rules may tend to overfit - making policy-analysis on the basis of the model a dubious task. We prefer to stick to the parsimonious Taylor rule. Third, both employment and the real wage are not sufficiently positively correlated with future output (rows 4 and 5, column 1).

\section{E Flexible Labor Market Experiments}

The impulse responses (Figures 1, 2, 4 and 5) show the estimated benchmark model along with counterfactual scenarios that are meant to illustrate the behaviour of the economy if the labor market were more flexible. In detail, they are constructed as follows:

1. A black solid line marks the impulse response when the estimated parameters (at the posterior mode) are used along with the baseline calibration.

2. A red dotted line marked by triangles shows the impulse responses when the estimated parameters of the model are used but for eliminating wage rigidity. We set the latter to a very small value, $\phi_{L}^{\text {new }}=1 . e-6$. This case shows how important the wage rigidity friction is. Clearly, the steady state relative to the estimated model is not changed by altering $\phi_{L}^{\text {new }}$.

3. A green dash-dotted line without markers shows the response when the estimated parameters of the model are used but the labor market is less rigid in the following sense: We assume that all workers almost immediately find a job in steady state (not necessarily outside of steady state) - this means there is an abundance of firms in the market. We set the probability of finding a job in steady state to about $1, \bar{s} \approx 1$, and the probability for a firm to find a worker close to zero, $\bar{q} \approx 0$.

- This changes the steady state of the model.

- In order to achieve these changes, vacancy posting costs need to be negligible, $\kappa \approx$ 0 . The efficiency of matching, $\sigma_{m}$, needs to be adjusted to guarantee well defined probability measures in steady state. 
Figure 7: Cross-Correlations.

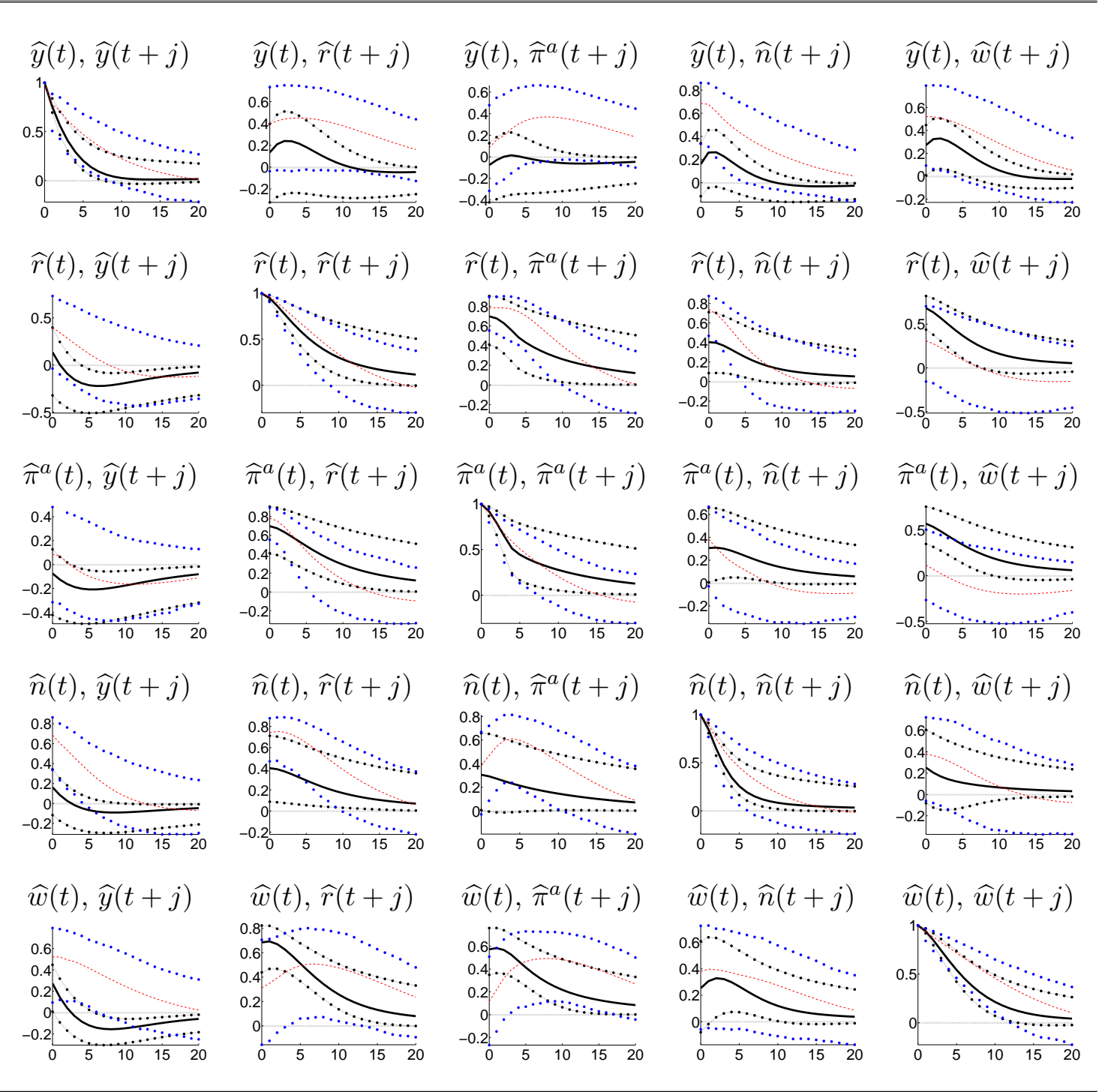

Notes: Cross-correlation vs data (VAR2). The black solid line marks the cross-correlation of the model at the posterior mode (or, it turns out after the simulations, almost equivalently the median crosscorrelation). The black dash-dotted lines mark corresponding $95 \%$ posterior coverage intervals (over the median). The red dashed line marks cross-correlations obtained from a VAR(2) without constants. Blue dots mark a $95 \%$ confidence interval (over the median) obtained from bootstrapping the same $\operatorname{VAR}(2)$ without constant. 
- We maintain the assumption that the marginal rate of substitution equals the wage rate in steady state, $\frac{\overline{m r s}}{\bar{w}}=1$, and that hours worked $\bar{h}=1 / 3$. These assumptions are satisfied by means of a change in the disutility of work scaling parameter, $\kappa_{h}$, and the level of unemployment benefits, $b$, relative to the estimated model.

- This leads to a replacement rate $\frac{b}{w h}=0.15$ instead of 0.5. Note that for each worker, unemployment becomes less costly (as he is sure to find a job next period), the replacement rate therefore needs to fall.

- With $\bar{s} \approx 1$, there is about full employment prior to production, so the number of searching workers is $\bar{u}=\rho$, which is another change to the steady state.

4. A blue dashed line without markers is the same as in 3 . but that we in addition assume a smaller separation rate, $\rho=0.07$. This implies

- a replacement rate of $\frac{b}{w h}=0.05$ instead of 0.5 .

5. A green dash-dotted line marked by circles is the same as in 3 . but for the fact that we let only the efficiency of matching, $\sigma_{m}$, change relative to the benchmark (to achieve a well defined probability measure) and let only vacancy posting costs, $\kappa$, change keeping unemployment benefits, $b$, and the scaling parameter to disutility of work, $\kappa_{h}$, (and all preference parameters) at the level as in the estimated version.

- This leads to the steady state not being efficient anymore $\frac{\overline{m r s}}{\bar{w}}=0.90$.

- $\bar{u}=0.08$.

- $\bar{h}=0.33$.

- $\frac{b}{w h}=0.51$., which is about the same replacement rate as in the benchmark case.

6. A blue dashed line marked by circles is the same as in 5 . but for the fact that we also assume $\rho=0.07$.

- This leads to the steady state not being efficient anymore $\frac{\overline{m r s}}{\bar{w}}=0.89$.

- $\bar{u}=0.07$.

- $\bar{h}=0.33$.

- $\frac{b}{\bar{w} \bar{h}}=0.51$. 


\section{F Nominal Wage Adjustment Costs and Calvo Wage Rigidity}

As a robustness check we entertained two further variants for modelling wage rigidity:

1. we examined whether modelling adjustment costs on nominal instead of real wages alters the behavior of the model in a significant manner.

2. we entertained a Calvo (1983) staggered framework to give an economic meaning to the size of the adjustment cost estimate $\phi_{L}^{\text {new }}$.

Our results, first, are not sensitive to the way we modelled wage rigidity. Second, the quadratic wage adjustment cost estimate in the benchmark model translates into moderate Calvo wage stickiness. Wages according to our estimates are reoptimized twice a year.

Ad 1. when we assume that adjusting nominal wages causes costs - not the adjustment of the real wage rate - instead of (18) we let profits be characterized by

$$
\psi_{t}(j):=x_{t} y_{t}^{I}(j)-w_{t}(j) h_{t}(j)-\frac{1}{2} \phi_{L}\left(\frac{w_{t}(j)}{w_{t-1}(j)} \frac{\Pi_{t}}{\bar{\Pi}}-1\right)^{2} .
$$

Overall, the behaviour of the economy is very similar to the economy under real wage adjustment costs and so are the posterior mode parameter estimates. The only difference appears in the response of the economy to a cost-push shock. We omit the figure here for brevity and refer to our IZA discussion paper No. 1902, p. 55, Figure 10.

Ad 2. we also experimented with Calvo type real wage rigidities at the individual firm/worker level instead of the quadratic adjustment costs. ${ }^{32}$ We keep the assumption of right-to-manage bargaining. That is, in each period the firm decides on the intensive margin (hours worked) taking into account the prevailing individual wage rate. In contrast to Gertler and Trigari (2005), who use efficient bargaining, we can therefore retain the intensive margin (hours choice). Let $\gamma_{w}$ be the probability that a firm-worker pair cannot update its wage. Instead of the wage equation (34) the Calvo model features the (mostly auxiliary) equations listed below.

Parameter estimates are very similar to the version with quadratic adjustment costs - we therefore do not report them here. The slope of wage adjustment costs, $\phi_{L}^{\text {new }}$ estimated for the benchmark model under quadratic adjustment costs translates to a Calvo wage stickiness of $\gamma_{w}=0.5$ at the posterior mode. So wages are reset twice a year.

$$
\widehat{G a p 1}_{t}=\frac{1-\beta(1-\rho)(1-s)}{1-\tilde{\beta}} \frac{1}{\frac{\phi}{1+\phi}-\frac{b}{w h}}\left(\widehat{w}_{t-1}^{*}-\widehat{w}_{t-1}\right)
$$

\footnotetext{
32 This implies full indexation of wages to inflation as is frequently found in the aggregate data; see e.g. Christiano, Eichenbaum, and Evans (2005), who find full indexation for US data, and Smets and Wouters (2003), who find substantial indexation for euro area data.
} 
where $\tilde{\beta}=\beta(1-\rho) \gamma_{w}$.

$$
\begin{aligned}
\widehat{G a p}_{t}= & \frac{1-\beta(1-\rho)(1-s)}{1-\tilde{\beta}} \frac{1}{\frac{\phi}{1+\phi}-\frac{b}{w h}}\left(\widehat{w}_{t-1}-\widehat{w}_{t}^{*}\right) . \\
\widehat{W U}_{t}= & \frac{1-\beta(1-\rho)(1-s)}{\frac{\phi}{1+\phi}-\frac{b}{w h}}\left(\widehat{w}_{t}^{*}+\frac{1}{1+\phi}\left(\widehat{\lambda}_{t}-\widehat{\kappa}_{h, t}\right)\right) \\
+ & \beta(1-\rho)(1-s) E_{t} \widehat{W U}_{t+1} \\
+ & \beta(1-\rho)(1-s)\left(\widehat{\lambda}_{t+1}-\widehat{\lambda}_{t}\right)+\tilde{\beta}(1-s) E_{t} \widehat{G a p 2}_{t+1} \\
+ & \tilde{\beta} E_{t} \widehat{G a p 1}_{t+1}-\beta(1-\rho) s \widehat{s}_{t} . \\
\widehat{J}_{t}= & \frac{1-\beta(1-\rho)}{\alpha-1}\left(\alpha \widehat{w}_{t}^{*}-\widehat{z}_{t}-\widehat{x}_{t}\right) \\
& +\frac{\tilde{\beta}}{1-\tilde{\beta}}\left(\frac{1-\gamma_{w}}{\gamma_{w}}+1-\beta(1-\rho)\right)\left(E_{t} \widehat{\lambda}_{t+1}-\widehat{\lambda}_{t}\right) \\
& +\frac{\tilde{\beta}}{\gamma_{w}} E_{t} \widehat{J}_{t+1} \\
& +\frac{\tilde{\beta}}{1-\tilde{\beta}}(1-\beta(1-\rho)) \frac{\alpha}{\alpha-1}\left(\widehat{w}_{t}^{*}-E_{t} \widehat{w}_{t+1}^{*}\right) .
\end{aligned}
$$

Wage bargaining FOC

$$
\begin{aligned}
& \widehat{W U}_{t}=\widehat{\delta}_{t}^{W}+\widehat{J}_{t}-\widehat{\delta}_{t}^{F} . \\
\widehat{\delta}_{t}^{W}= & \frac{1-\tilde{\beta}}{(\alpha-1)}\left(1+\frac{\alpha-1-\phi}{\alpha-1}\right) \widehat{w}_{t}^{*} \\
& -\frac{1-\tilde{\beta}}{(\alpha-1)^{2}}(\alpha-1-\phi)\left(\widehat{x}_{t}+\widehat{z}_{t}\right) \\
& +\frac{1-\tilde{\beta}}{\alpha-1}\left(\widehat{\lambda}_{t}-\widehat{\kappa}_{h, t}\right) \\
& +\tilde{\beta}\left(E_{t} \widehat{\lambda}_{t+1}-\widehat{\lambda}_{t}\right) \\
& +\tilde{\beta} \frac{1+(\alpha-1-\phi) /(\alpha-1)}{\alpha-1}\left(\widehat{w}_{t}^{*}-E_{t} \widehat{w}_{t+1}^{*}\right) \\
& +\tilde{\beta} E_{t} \widehat{\delta}_{t+1}^{W} \cdot \\
\widehat{\delta}_{t}^{F}=\frac{1-\tilde{\beta}}{\alpha-1}\left(\widehat{w}_{t}^{*}-\widehat{x}_{t}-\widehat{z}_{t}\right)+ & \frac{\tilde{\beta}}{\alpha-1}\left(\widehat{w}_{t}^{*}-E_{t} \widehat{w}_{t+1}^{*}\right)+\tilde{\beta}\left(E_{t} \widehat{\lambda}_{t+1}-\widehat{\lambda}_{t}\right)+\tilde{\beta} E_{t} \widehat{\delta}_{t+1}^{F} .
\end{aligned}
$$

Aggregate wage

$$
\widehat{w}_{t}=\gamma_{w} \widehat{w}_{t-1}+\left(1-\gamma_{w}\right) \widehat{w}_{t}^{*} .
$$

Vacancy Posting

$$
\begin{aligned}
\widehat{J}_{t}= & \frac{1-\beta(1-\rho)}{\alpha-1}\left(\alpha \widehat{w}_{t}^{*}-\widehat{z}_{t}-\widehat{x}_{t}\right) \\
& +(1-\rho) \beta\left(\widehat{\kappa}_{t}-\widehat{\lambda}_{t}-\widehat{q}_{t}\right) \\
& +\frac{\tilde{\beta}}{1-\tilde{\beta}}(1-\beta(1-\rho)) \frac{\alpha}{\alpha-1}\left(\widehat{w}_{t}^{*}-\widehat{w}_{t}\right) .
\end{aligned}
$$




\section{European Central Bank Working Paper Series}

For a complete list of Working Papers published by the ECB, please visit the ECB's website (http://www.ecb.int)

594 “The euro's trade effects" by R. Baldwin, comments by J. A. Frankel and J. Melitz, March 2006

595 "Trends and cycles in the euro area: how much heterogeneity and should we worry about it?" by D. Giannone and L. Reichlin, comments by B. E. Sørensen and M. McCarthy, March 2006.

596 "The effects of EMU on structural reforms in labour and product markets" by R. Duval and J. Elmeskov, comments by S. Nickell and J. F. Jimeno, March 2006.

597 "Price setting and inflation persistence: did EMU matter?" by I. Angeloni, L. Aucremanne, M. Ciccarelli, comments by W. T. Dickens and T. Yates, March 2006.

598 "The impact of the euro on financial markets" by L. Cappiello, P. Hördahl, A. Kadareja and S. Manganelli, comments by X. Vives and B. Gerard, March 2006.

599 "What effects is EMU having on the euro area and its Member Countries? An overview" by F. P. Mongelli and J. L. Vega, March 2006.

600 "A speed limit monetary policy rule for the euro area" by L. Stracca, April 2006.

601 "Excess burden and the cost of inefficiency in public services provision" by A. Afonso and V. Gaspar, April 2006.

602 "Job flow dynamics and firing restrictions: evidence from Europe" by J. Messina and G. Vallanti, April 2006.

603 "Estimating multi-country VAR models" by F. Canova and M. Ciccarelli, April 2006.

604 "A dynamic model of settlement" by T. Koeppl, C. Monnet and T. Temzelides, April 2006.

605 “(Un)Predictability and macroeconomic stability” by A. D’Agostino, D. Giannone and P. Surico, April 2006.

606 "Measuring the importance of the uniform nonsynchronization hypothesis" by D. A. Dias, C. Robalo Marques and J. M. C. Santos Silva, April 2006.

607 "Price setting behaviour in the Netherlands: results of a survey" by M. Hoeberichts and A. Stokman, April 2006.

608 "How does information affect the comovement between interest rates and exchange rates?" by M. Sánchez, April 2006.

609 "The elusive welfare economics of price stability as a monetary policy objective: why New Keynesian central bankers should validate core inflation" by W. H. Buiter, April 2006.

610 "Real-time model uncertainty in the United States: the Fed from 1996-2003" by R. J. Tetlow and B. Ironside, April 2006. 
611 "Monetary policy, determinacy, and learnability in the open economy" by J. Bullard and E. Schaling, April 2006.

612 "Optimal fiscal and monetary policy in a medium-scale macroeconomic model" by S. Schmitt-Grohé and M. Uribe, April 2006.

613 "Welfare-based monetary policy rules in an estimated DSGE model of the US economy" by M. Juillard, P. Karam, D. Laxton and P. Pesenti, April 2006.

614 "Expenditure switching vs. real exchange rate stabilization: competing objectives for exchange rate policy" by M. B. Devereux and C. Engel, April 2006.

615 "Quantitative goals for monetary policy" by A. Fatás, I. Mihov and A. K. Rose, April 2006.

616 "Global financial transmission of monetary policy shocks" by M. Ehrmann and M. Fratzscher, April 2006.

617 "New survey evidence on the pricing behaviour of Luxembourg firms" by P. Lünnemann and T. Y. Mathä, May 2006.

618 "The patterns and determinants of price setting in the Belgian industry" by D. Cornille and M. Dossche, May 2006.

619 "Cyclical inflation divergence and different labor market institutions in the EMU" by A. Campolmi and E. Faia, May 2006.

620 "Does fiscal policy matter for the trade account? A panel cointegration study" by K. Funke and C. Nickel, May 2006.

621 "Assessing predetermined expectations in the standard sticky-price model: a Bayesian approach" by P. Welz, May 2006.

622 "Short-term forecasts of euro area real GDP growth: an assessment of real-time performance based on vintage data" by M. Diron, May 2006.

623 "Human capital, the structure of production, and growth" by A. Ciccone and E. Papaioannou, May 2006.

624 "Foreign reserves management subject to a policy objective" by J. Coche, M. Koivu, K. Nyholm and V. Poikonen, May 2006.

625 "Sectoral explanations of employment in Europe: the role of services" by A. D'Agostino, R. Serafini and M. Ward-Warmedinger, May 2006.

626 "Financial integration, international portfolio choice and the European Monetary Union" by R. A. De Santis and B. Gérard, May 2006.

627 "Euro area banking sector integration: using hierarchical cluster analysis techniques" by C. Kok Sørensen, J. M. Puigvert Gutiérrez, May 2006.

628 "Long-run money demand in the new EU Member States with exchange rate effects" by C. Dreger, H.-E. Reimers and B. Roffia, May 2006.

629 "A market microstructure analysis of foreign exchange intervention" by P. Vitale, May 2006. 
630 “Implications of monetary union for catching-up member states” by M. Sánchez, May 2006.

631 "Which news moves the euro area bond market?" by M. Andersson, L. J. Hansen and S. Sebestyén, May 2006.

632 "Does information help recovering structural shocks from past observations?" by D. Giannone and L. Reichlin, May 2006.

633 "Nowcasting GDP and inflation: the real-time informational content of macroeconomic data releases” by D. Giannone, L. Reichlin and D. H. Small, May 2006.

634 "Expenditure reform in industrialised countries: a case study approach" by S. Hauptmeier, M. Heipertz and L. Schuknecht, May 2006.

635 "Identifying the role of labor markets for monetary policy in an estimated DSGE model" by K. Christoffel, K. Kuester and T. Linzert, June 2006. 
